\title{
Ventral Hippocampal Input to the Prelimbic Cortex Dissociates the Context from the Cue Association in Trace Fear Memory
}

\author{
Robert C. Twining, Katie Lepak, Adam J. Kirry, and ${ }^{\circledR}$ Marieke R. Gilmartin \\ Department of Biomedical Sciences, Marquette University, Milwaukee, Wisconsin 53233
}

The PFC, through its high degree of interconnectivity with cortical and subcortical brain areas, mediates cognitive and emotional processes in support of adaptive behaviors. This includes the formation of fear memories when the anticipation of threat demands learning about temporal or contextual cues, as in trace fear conditioning. In this variant of fear learning, the association of a cue and shock across an empty trace interval of several seconds requires sustained cue-elicited firing in the prelimbic cortex (PL). However, it is unknown how and when distinct PL afferents contribute to different associative components of memory. Among the prominent inputs to PL, the hippocampus shares with PL a role in both working memory and contextual processing. Here we tested the necessity of direct hippocampal input to the PL for the acquisition of trace-cued fear memory and the simultaneously acquired contextual fear association. Optogenetic silencing of ventral hippocampal (VH) terminals in the PL of adult male Long-Evans rats selectively during paired trials revealed that direct communication between the VH and PL during training is necessary for contextual fear memory, but not for trace-cued fear acquisition. The pattern of the contextual memory deficit and the disruption of local PL firing during optogenetic silencing of VH-PL suggest that the VH continuously updates the PL with the current contextual state of the animal, which, when disrupted during memory acquisition, is detrimental to the subsequent rapid retrieval of aversive contextual associations.

Key words: memory formation; fear conditioning; optogenetics; working memory

\section{Significance Statement}

Learning to anticipate threat from available contextual and discrete cues is crucial for survival. The prelimbic cortex is required for forming fear memories when temporal or contextual complexity is involved, as in trace fear conditioning. However, the respective contribution of distinct prelimbic afferents to the temporal and contextual components of memory is not known. We report that direct input from the ventral hippocampus enables the formation of the contextual, but not tracecued, fear memory necessary for the subsequent rapid expression of a fear response. This finding dissociates the contextual and working-memory contributions of prelimbic cortex to the formation of a fear memory and demonstrates the crucial role for hippocampal input in contextual fear learning.

\section{Introduction}

The PFC is an integral component of a neural system that mediates cognitive and emotional processes and regulates a wide range of adaptive behaviors (Euston et al., 2012; Godsil et al., 2013; Hiser and Koenigs, 2018). Through its interconnectivity

Received June 19, 2019; revised Mar. 2, 2020; accepted Mar. 5, 2020.

Author contributions: R.C.T and M.R.G. designed the experiments and wrote the manuscript; R.C.T. performed the surgeries and analyzed the data; R.C.T. and K.L. ran the experiments; K.L. and A.J.K. performed histological analysis; A.J.K. provided critical feedback on the manuscript.

This work was supported by Whitehall Foundation 2014-8-67 and National Science Foundation IOS:1558121 to M.R.G.

The authors declare no competing financial interests.

Correspondence should be addressed to Marieke R. Gilmartin at marieke.gilmartin@marquette.edu or Robert C. Twining at robert.twining@marquette.edu.

https://doi.org/10.1523/JNEUROSCI.1453-19.2020

Copyright $\odot 2020$ the authors with cortical and subcortical areas, the PFC integrates previously learned information with current emotional and motivational states of the animal to guide behavior. However, it is increasingly clear that the PFC is crucial for the initial encoding of some memories, including associative fear memories. The prelimbic (PL) and anterior cingulate cortices of the rodent are necessary for fear learning when temporal or contextual processing is needed (Han et al., 2003; Zhao et al., 2005; Gilmartin and Helmstetter, 2010; Guimarais et al., 2011; Gilmartin et al., 2013b, 2014; Heroux et al., 2017; Robinson-Drummer et al., 2017; Kirry et al., 2019). The acquisition of trace fear memory includes both temporal and contextual components for which the PL is necessary, but how these components are regulated by afferent input to $\mathrm{PL}$ is unknown. Trace fear conditioning requires subjects to associate an auditory conditional stimulus (CS) and an aversive 
footshock unconditional stimulus (UCS) that are separated in time. The presence of this temporal gap recruits episodic memory systems, including the hippocampus and PFC. Functional disruption of either area severely impairs the acquisition of fear to the trace-CS and also the background context-shock association formed at the same time (Yoon and Otto, 2007; Czerniawski et al., 2009, 2011; Esclassan et al., 2009; Gilmartin and Helmstetter, 2010; Guimarais et al., 2011; Gilmartin et al., 2012, 2013a). In PL, a subset of neurons exhibit sustained increases in firing in response to a trace-CS and throughout the trace interval, similar to cue-elicited delay-cell activity in primate dorsolateral PFC during working-memory tasks (Baeg et al., 2001; Gilmartin and McEchron, 2005). Optogenetic inhibition of PL firing selectively during the trace interval prevented animals from learning the predictive cue-shock relationship while leaving contextual learning intact (Gilmartin et al., 2013b). Thus, a specific PL signal promotes the anticipation of threat through a working-memory-like function, but how specific inputs to the PFC contribute to the nature of this signal and learning is unknown.

Among the major afferents to the PFC, the ventral hippocampus $(\mathrm{VH})$ is a likely partner in memory formation for salient events. The $\mathrm{VH}$ receives valence-encoded information from both CS-responsive and appetitive UCS-responsive amygdala neurons (Beyeler et al., 2016, 2018), and VH neurons respond robustly to an aversive UCS (Weible et al., 2006). The PL PFC receives monosynaptic input from the $\mathrm{VH}$, which is glutamatergic (Jay et al., 1989; Jay and Witter, 1991; Cenquizca and Swanson, 2007; Hoover and Vertes, 2007; Parent et al., 2010). A functional interaction between the hippocampus and PFC has been implicated, but not demonstrated, in cue encoding during a related associative paradigm, trace eyeblink conditioning. Prefrontal firing was phase-locked to hippocampal theta, and sustained prefrontal firing to the CS was observed only on trials delivered during hippocampal theta (Darling et al., 2011). Disrupted hippocampal-prefrontal connectivity is associated with working-memory deficits in humans diagnosed with schizophrenia (Sigurdsson and Duvarci, 2015; Schneider et al., 2017) and with poor spatial working-memory performance in genetic mouse models of schizophrenia (Sigurdsson et al., 2010). Moreover, optogenetic inhibition of the VH-PL pathway in WT mice produced similar working-memory deficits (Spellman et al., 2015). These deficits were specific to the encoding of spatial cues, consistent with recent work highlighting the importance of VH-PL for contextual processing. Inhibition of $\mathrm{VH}$ input disrupted prefrontal encoding of aversive locations in anxiety-provoking contexts (Padilla-Coreano et al., 2016), and silencing VH-IL impaired context-modulated fear renewal after extinction (Marek et al., 2018). These findings raise the question of whether VH-PL mediates prefrontal encoding of cues more generally to include nonspatial temporal associative learning in addition to spatial working memory or whether VH-PL input preferentially conveys contextual information. Here we use projection-specific optogenetics to selectively silence VH terminals in PL during trace fear conditioning and test the hypothesis that both cued and contextual fear memory acquisition depends on VH input to PL.

\section{Materials and Methods}

Subjects

Adult male Long-Evans rats (325 g; Envigo) were housed individually in an Association for Assessment and Accreditation of Laboratory Animal Care-accredited vivarium and maintained on a $14 \mathrm{~h}: 10 \mathrm{~h}$ light/dark cycle. Rats received food and water ad libitum throughout the experiment.
Twenty-eight rats were used in this study: 24 for behavior and 4 for electrophysiological verification of optogenetic terminal silencing. All procedures were in accordance with the National Institutes of Health guidelines and approved by the Marquette University Institutional Animal Care and Use Committee.

\section{Optogenetic viral constructs}

The adeno-associated viral vector containing the light-sensitive archaerhodopsin from Halorubrum strain TP009 (ArchT; rAAV9/CAG-ArchTGFP) was prepared by R. Jude Samulski and the University of North Carolina Vector Core from material provided by Ed Boyden and the Massachusetts Institute of Technology. Inactive control virus AAV9/ CAG-GFP was also obtained from the University of North Carolina Vector Core.

\section{Surgical procedures}

After a minimum of $3 \mathrm{~d}$ of handling, rats underwent intracranial surgery under isoflurane anesthesia ( $1 \%-2 \%$ isoflurane in $\left.100 \% \mathrm{O}_{2}\right)$. Perioperative pain was managed with carprofen (Rimadyl, $5 \mathrm{mg} / \mathrm{kg}$, s.c.; Henry Schein Medical) $1 \mathrm{~h}$ before surgery and the following day. During surgery, the rat was secured in a stereotaxic instrument (David Kopf), and a midline incision was made in the scalp. The fascia was retracted to expose the skull, and small craniotomies were drilled above the target sites. Rats were bilaterally injected with the neural silencer AAV9/CAG-ArchT-GFP (750 nl/ side; titer: $3 \times 1012)$ or inactive control virus AAV9/CAG-GFP $(750 \mathrm{nl} /$ side; titer: $2 \times 1012)$ into the $\mathrm{VH}(0.75 \mu \mathrm{l} /$ side at $0.1 \mu \mathrm{l} / \mathrm{min}$; AP $-5.6, \mathrm{ML}$ $\pm 5.5, \mathrm{DV}-7.0$ ). Injectors were left in place for $10 \mathrm{~min}$ after injection to allow the virus to completely diffuse away from the injector. After 1014 weeks of expression and recovery, optic fibers in ceramic ferrules (Thorlabs) were implanted bilaterally in the PL at a $12^{\circ}$ angle (AP 3.0, ML $\pm 1.44, \mathrm{DV}-3.07)$. Four rats were implanted with an optrode 13-19 weeks after virus injection. The optrode consisted of an optic fiber attached to a 16-channel microwire electrode array ( $35 \mu \mathrm{m}$ tungsten, Innovative Neurophysiology; or $50 \mu \mathrm{m}$ stainless steel, Microprobes). Following 7$14 \mathrm{~d}$ of recovery from this second surgery, rats were acclimated to transport and handling for $3 \mathrm{~d}$ before experimental manipulations.

\section{Unit recording}

An experimentally naive rat from the same surgical cohort was implanted with a 16-channel optrode and bilateral fiberoptic cannula targeting the PL cortex to characterize the effects of $\mathrm{VH}$ terminal silencing on PL neuronal activity (see Fig. $1 B-D$ ). The rat was acclimated to the test chamber the day before the recording session. The recording session was $50 \mathrm{~min}$ in length; and after a baseline period of $2 \mathrm{~min}, 12$ trials of laser light were delivered to PL. Each trial consisted of $70 \mathrm{~s}$ of laser illumination to correspond to the parameters used in the behavioral study $(15 \mathrm{~mW}, 532 \mathrm{~nm}$; intertrial interval $=210 \pm 70 \mathrm{~s})$. Recordings were conducted with microelectrode arrays featuring 16 tungsten wires (35 $\mu \mathrm{m}$ in diameter) arranged in a $2 \times 8$ configuration (Innovative Neurophysiology). A fiberoptic cannula was cemented into a groove in the center of the array and terminated at $0.5 \mathrm{~mm}$ above the electrode tips. Another identical fiberoptic cannula was implanted on the contralateral side. Three additional rats were injected with ArchT bilaterally in $\mathrm{VH}$ and implanted with an optrode (50 $\mu \mathrm{m}$ stainless steel; Microprobes) unilaterally in PL and an optic fiber in contralateral PL. These rats received two daily sessions of 4 CS-alone trials followed by 6 CS-traceUCS trials using the same stimulus parameters described below. Laser light ( $15 \mathrm{~mW} ; 532 \mathrm{~nm}$ ) was delivered during the CS and trace interval of each paired trial, starting $1 \mathrm{~s}$ before CS onset ( $31 \mathrm{~s}$ total per trial). For recording, the rats were connected to a flexible recording cable via Zif-clip headstage adaptor and attached to a quiet, electrically shielded 64-channel motorized commutator equipped for fiberoptic light delivery (Tucker-Davis Technologies). Prefrontal cortical activity was recorded differentially between each active wire and the common average reference. Online isolation and discrimination were accomplished using a commercially available neurophysiological system from Tucker-Davis Technologies. The system consists of an intuitive software interface (Synapse Suite, Tucker-Davis Technologies) and high-speed analog to digital signal processing with multiple parallel DSPs housed in a 
A

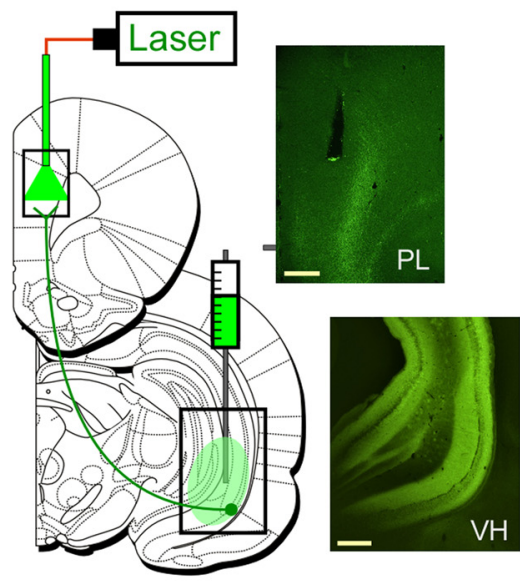

D

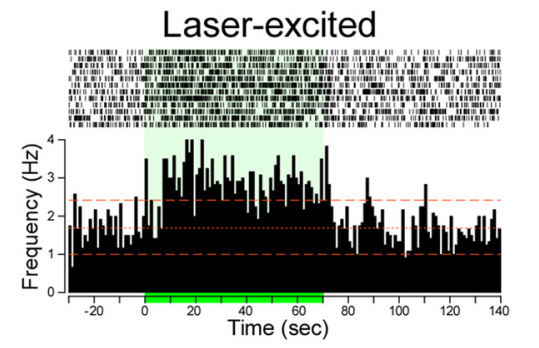

B

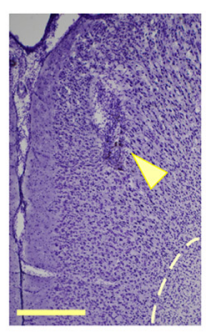

C

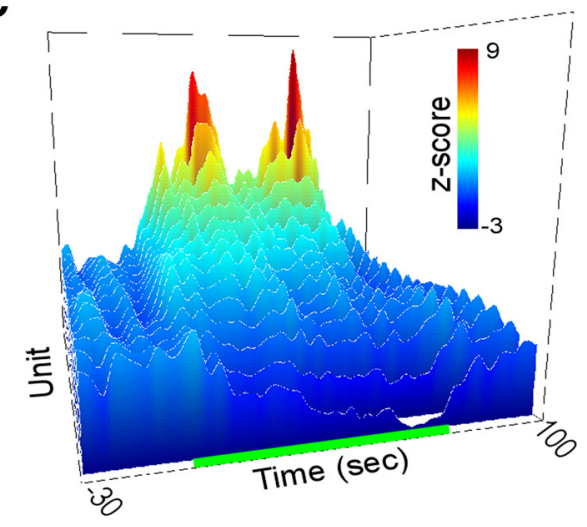

Laser-inhibited

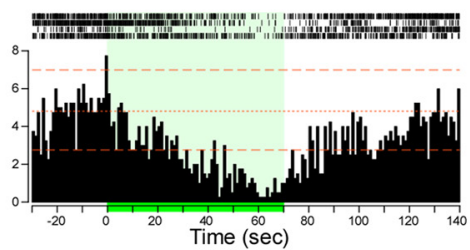

Laser-nonresponsive

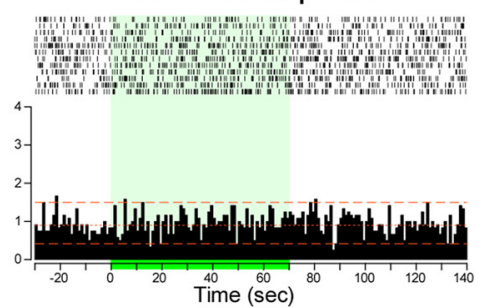

E

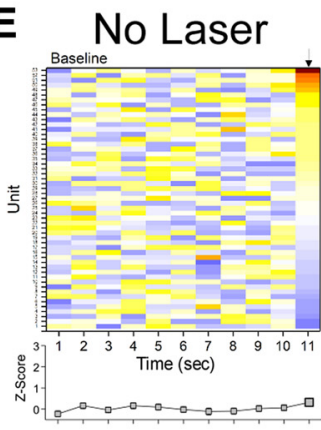

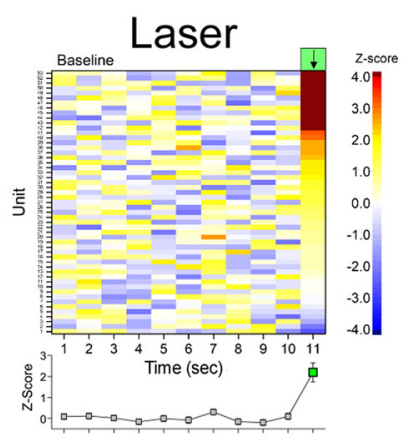

F

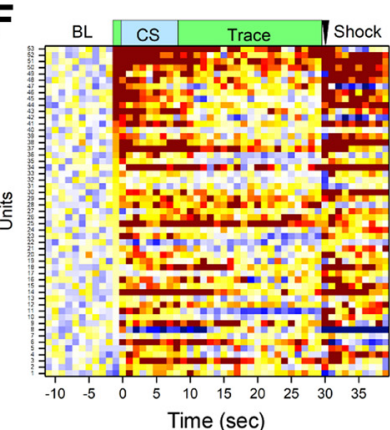

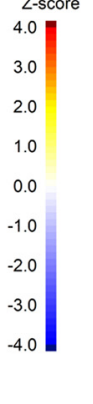

G CS-responsive

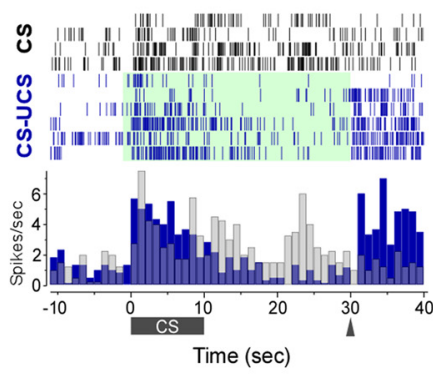

Figure 1. Optogenetic control of VH input to PL. A, Diagram of the projection-targeting approach and representative images of AAV9/CAG-ArchT-GFP virus expression in VH and PL and fiber placement in PL. B, Nissl-stained section of PL showing the location of the implanted optrode for the rat in $\boldsymbol{C}$ (arrowhead; Bregma level 3.40). $\boldsymbol{C}$, Averaged normalized firing of each neuron recorded in the PL of a naive rat (Gaussian-smoothed $1 \mathrm{~s}$ bins). Each trace represents the activity averaged over 12 trials in which VH terminals in the PL were silenced for $70 \mathrm{~s}$ (green bar). $\boldsymbol{D}$, Perievent histograms (spikes/s in 1s bins; 12 trials) and rasters for an example laser-responsive PL unit that showed an increase, an example that showed a decrease in firing, and one example laser-nonresponsive PL unit. The laser-inhibited unit emerged late in the session, so the rasters show the four trials of laser delivery for this unit. Green bar and shading represent laser onset and offset. Orange dashed lines indicate $\pm 95 \% \mathrm{Cl}$ around average baseline firing rate (middle line). $\boldsymbol{E}-\mathbf{G}, \mathrm{PL}$ activity from 3 trained rats in which laser was delivered during the CS and trace interval of paired trials, but not the preceding CS-alone trials. E, Heat maps of averaged normalized firing of 53 neurons during the baseline period before laser-free CS-alone trials (left) or during the baseline period before laser delivery on CS-paired trials (right). Units were ranked based on normalized activity in the 11th second of baseline, which is the time of laser onset on paired trials (right panel only). Silencing VH terminals in PL significantly altered the proportion of PL units with $>0.5 z$ score change during this bin compared with the rest of baseline (Bin 11 , no laser vs laser: $\left.\chi_{(2,53)}^{2}=11.99, p=0.0025\right)$. Below each heat map in $\boldsymbol{E}$ is the average normalized activity \pm SEM during the corresponding bin. $\boldsymbol{F}$, Heat map of averaged normalized firing of units during the paired trials, again ranked by activity in the final second of baseline (laser onset). G, Perievent histogram (CS-alone and CS-UCS histograms overlaid) and raster for an example unit during paired trials on day 2 of trace conditioning. This unit, which was nonresponsive to laser onset, exhibited sustained firing to the CS during laser-free CS-alone retention trials (gray raster and histogram). The CS-evoked response was reduced transiently (rows 1-3 of CS-UCS raster) by VH-PL silencing during paired trials (blue raster and histogram). Histology scale bar, $500 \mu \mathrm{m}$. Coronal diagrams were adapted from (Paxinos and Watson, 2007) with permission.

dedicated BioAmp processor (RZ2, Tucker-Davis Technologies) enabling continuous isolation of neuronal signals based on waveform analysis. Criteria for discriminating individual waveforms corresponding to a single neuron were accomplished using a supervised template and principal component analysis in Offline Sorter (Plexon 4.4.0).

\section{Fear conditioning}

Training and testing were conducted in Med Associates conditioning chambers (internal dimensions: $30.5 \times 24.1 \times 29.2 \mathrm{~cm}$ ), each housed in a sound attenuating outer chamber and illuminated with an LED lamp attached to the outer chamber. Ventilation fans in the outer chamber provided 55-60 dB background noise, and the auditory cue was delivered through a speaker centered in one side wall of the conditioning chamber. Stainless-steel bars ( $4.8 \mathrm{~mm}$ diameter, spaced $16 \mathrm{~mm}$ apart) on the floor of the chamber served to deliver a scrambled footshock. The training chamber (Context A) was cleaned and scented with a 70\% ethanol solution, and the CS test chamber (Context B) was cleaned and scented with acetic acid (5\%). Context B differed from Context A in odor, texture, and illumination as previously described (Kirry et al., 2018). In addition, transport between the colony room and the testing room was altered from that used for training: rats were covered during transport, and an alternate route was used. Figure $2 B$ shows the experimental design and timeline. Before conditioning, the rats were acclimated to the optical patch cable tethers in the conditioning chamber for 


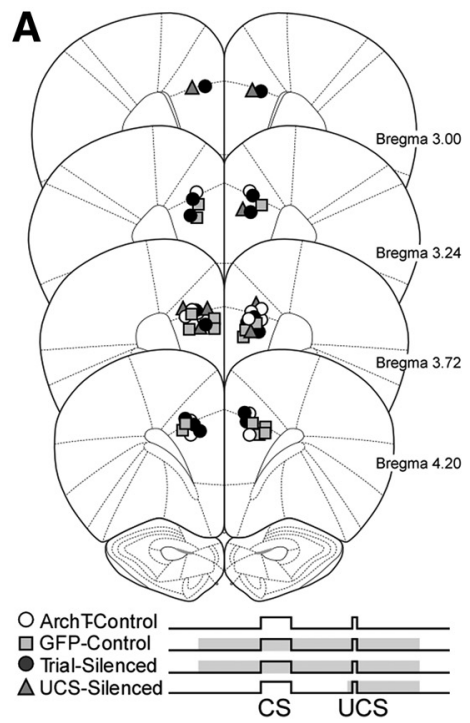

B

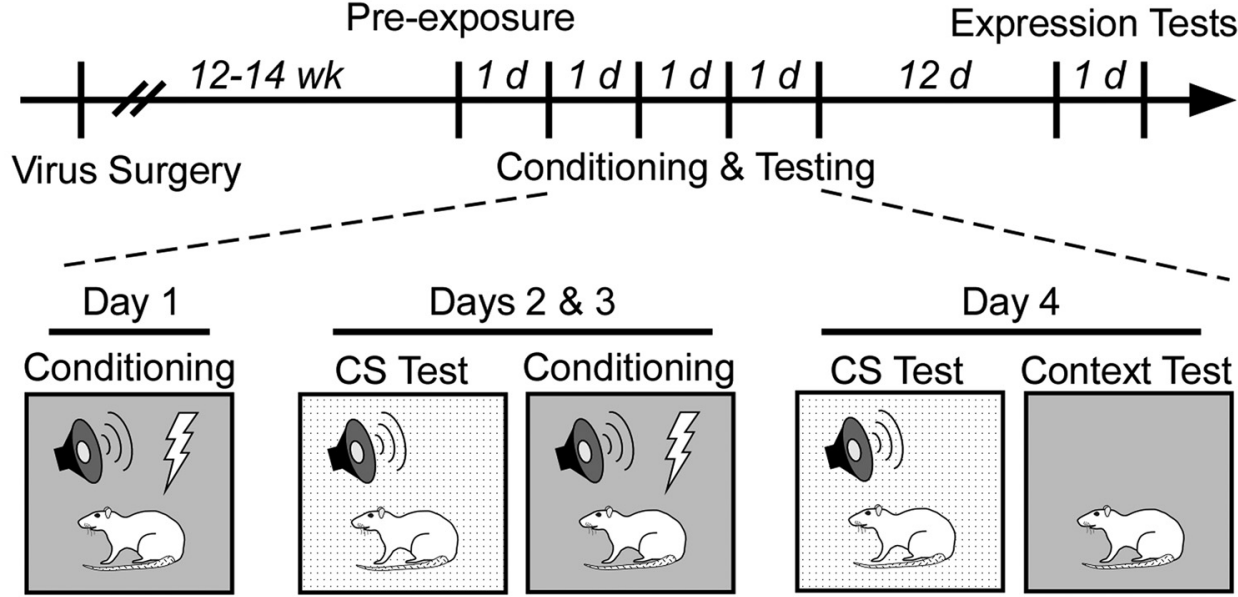

Figure 2. Fiber placement and experimental design. $A$, Fiber placements for rats in each of the four groups: ArchT unsilenced controls (ArchT-control; $n=8$ ), ArchT Trial-silenced (Trialsilenced; $n=7$ ), inactive virus control (GFP-control; $n=8$ ), and ArchT UCS-silenced (UCS-silenced; $n=4$ ). Shaded bars in stimulus diagrams represent timing of laser delivery during paired trials for each group. $\boldsymbol{B}$, Procedural timeline of training and testing following virus injection. Preexposure consisted of 2 nonreinforced $30 \mathrm{~s}$ presentations of a $6 \mathrm{kHz}$ tone and white noise $\mathrm{CS}$. Training consisted of 2 pairings of a $10 \mathrm{~s} C S$ with a $1 \mathrm{~s}$ footshock UCS $(0.6 \mathrm{~mA})$ separated by a $20 \mathrm{~s}$ trace interval each day for $3 \mathrm{~d}$. A CS test in a shifted context was administered before training on days 2 and 3. On day 4, a CS test was followed by a CT, with no further training. Each CS test consisted of two $30 \mathrm{~s}$ tones and four $30 \mathrm{~s}$ CSs. All rats received the same training and testing protocol with one exception: only the ArchT-control and Trial-silenced active virus groups received two additional CTs $12 \mathrm{~d}$ later, with or without laser delivery to assess VH-PL silencing on the expression of fear (Expression Tests; see Figure 6). Coronal diagrams were adapted from (Paxinos and Watson, 2007) with permission.

$5 \mathrm{~min}$. They then received two nonreinforced presentations each of a $6 \mathrm{kHz}$ tone and white noise $(30 \mathrm{~s} ; 72 \mathrm{~dB})$. Trace fear conditioning was then administered over the next 3 consecutive days, two trials per day. This procedure was modified from our previous single-day 6-trial training protocol (Gilmartin et al., 2012, 2013b; Kirry et al., 2018) to be sensitive to impaired or enhanced acquisition. Each trial consisted of a $10 \mathrm{~s}$ white noise CS $(72 \mathrm{~dB})$ followed by a $1 \mathrm{~s}$ footshock UCS $(0.6 \mathrm{~mA})$, which was delivered $20 \mathrm{~s}$ after CS offset (20 s trace interval). The intertrial interval was $240 \mathrm{~s}$. A 6 min baseline period was used on each day and served as the contextual fear retention test. Cued fear testing occurred in Context B $5 \mathrm{~h}$ before training on each day. After a 2 min baseline period, rats received two tone presentations $(30 \mathrm{~s}, 6 \mathrm{kHz}, 72 \mathrm{~dB}$ ) followed by four CS presentations (30s, $72 \mathrm{~dB}$ ). Stimulus presentations were separated by $120 \mathrm{~s}$. No laser light was delivered during these test sessions. To assess the effects of VH-PL silencing on the retrieval of context fear, two additional context test (CT) sessions (Expression tests) were administered 12 and $13 \mathrm{~d}$ after the final CS test session. On these days, rats were reintroduced to the training chamber for $8 \mathrm{~min}$. Laser light was delivered to the Trial group, but not the Control group, during the first test. Laser light was delivered to the Control group, but not the Trial group, during the second test.

\section{Optogenetic silencing of VH-PL terminals}

Optic fiber implants were positioned above VH terminals in the PL (see Figs. $1 A, 2 A)$. Laser light $\left(532 \mathrm{~nm}, 15 \mathrm{~mW}, 5 \mathrm{~mW} / \mathrm{mm}^{2}\right.$ estimated irradiance at $1.0 \mathrm{~mm}$ through brain tissue; OptoEngine) was delivered through a single multimode patch cord coupled to a fiberoptic rotary joint (Doric Lenses), which split the light to two fibers for bilateral light delivery. Light delivery was controlled with TTL pulses from within the FreezeScan 2.0 software (CleverSys). Opaque shrink tubing was placed over the ferrules to prevent external illumination from serving as a visual cue. For rats in the Trial-silenced $(n=7)$ and GFP-control $(n=8)$ groups, light was delivered on each trial continuously for $70 \mathrm{~s}$, starting $20 \mathrm{~s}$ before CS onset and ending $20 \mathrm{~s}$ after UCS offset. The rationale for this timing was to capture the relevant time point of VH-PL communication during trace conditioning, which is so far unknown. We therefore silenced terminals across the CS-trace-UCS trial while still maintaining a temporally limited disruption of the connection within the overall training session. While ArchT-expressing cells respond immediately to light delivery, silencing ArchT-expressing terminals several seconds before and after the onset of each trial ensures that network changes due to silencing are in effect at CS onset as well as encompasses UCS-evoked firing that lasts for several seconds after UCS offset (Gilmartin and McEchron, 2005). The same timing of laser control was administered to ArchT-control rats $(n=8)$, but light was blocked from entering the brain by an opaque barrier. This served as a control for viral expression of ArchT and presence of laser illumination during the trial period. For rats in the UCS-silenced group $(n=4)$, light was delivered on each trial for $22 \mathrm{~s}$ beginning $1 \mathrm{~s}$ before UCS onset and ending $20 \mathrm{~s}$ after UCS offset. This group was added after the initial experiment to determine whether VH-PL silencing during the shock was sufficient to impair contextual fear learning. During each of two expression tests, laser light was delivered continuously for $60 \mathrm{~s}$ twice during the session at 0-60 $\mathrm{s}$ and again at 240-300 s. During the first expression test, the light was blocked in the Control group, as during training. During the second expression test, light was allowed into the brain for the Control group but blocked from entering the brain of the Trial group.

\section{Experimental design and statistical analyses}

Freezing was defined as the cessation of all movement, except that needed for respiration, and was used as the measure of conditional fear during all training and testing sessions (Fanselow and Bolles, 1979). Freezing was scored automatically using FreezeScan 2.0 (CleverSys). Scoring parameters were chosen to produce scores that match handscored results, conducted by a trained observer $(r=0.99)$. All statistical analyses were performed with Statistica version 13 (Statsoft). Group differences in freezing were analyzed using mixed-model and repeatedmeasures ANOVAs for acquisition, CS retention, context retention, and latency to freeze during context retention. CS retention: mixed-model ANOVAs varied a between-subjects factor of Group (Laser or Viral Condition) across 2 within-subjects factors of Stimulus Period (Period: Baseline, Unpaired Tone, CS, or Trace period following Tone or CS offset) by Test Day (days 1-3). Context retention: mixed-model ANOVAs varied a between-subjects factor of Group (Laser or Viral condition) across 2 within-subjects factors of (Bin $\times$ Day). Freezing to the context was analyzed in $30 \mathrm{~s}$ bins for the $5 \mathrm{~min}$ of laser- and stimulus-free context reexposure, just before the current day's training trials. For acquisition, we analyzed CS + Trace interval (30s) bins by trial across 
days. Freezing was analyzed across baseline $2 \mathrm{~min}$, Unpaired Tone (30 s), Tone-offset (30 s), CS (30 s), and CS-offset (Trace, $30 \mathrm{~s})$ in $30 \mathrm{~s}$ bins and averaged across their respective category. To determine relative group differences in fear memory accuracy, a discrimination index was calculated within subjects (CS freezing/(tone freezing + CS freezing); (CS-offset freezing/(tone-offset freezing + CS-offset freezing)) and averaged by group with $95 \%$ CIs. The CIs were drawn around the generalization point, defined by equivalent freezing to the CS and the unpaired tone $(\mathrm{GP}=0.50)$. Fisher's least significant difference tests were used to make planned pairwise comparisons when ANOVAs revealed an appropriate significant main effect or interaction, whereas the Holm-Sidak procedure was used to keep familywise $\alpha$ level at 0.05 for post hoc analyses. For pairwise comparisons, effect sizes were calculated using Cohen's $d$ with the pooled SD as standardizer for between-group effects and Cohen's $d_{\mathrm{RM}}$ for within-group effects. For all ANOVA results, effect sizes were calculated using partial $\eta$ squared $\left(\eta_{\mathrm{p}}^{2}\right)$. Pearson's $\chi^{2}$ test was used to analyze the proportion of neurons exhibiting excitatory or inhibitory responses to terminal silencing compared with baseline.

\section{Histology}

At the end of the experiment, rats were deeply anesthetized with concentrated isoflurane in a narcosis chamber, transcardially perfused with 0.1 M PBS followed by $10 \%$ buffered formalin, and the brains were placed in fixative overnight. The following day, brains were transferred to a $30 \%$ sucrose solution (in $0.1 \mathrm{M}$ phosphate buffer) for cryoprotection. Brains were then frozen, sectioned coronally $(40 \mu \mathrm{m})$, and mounted on glass slides. Every other section was stained with cresyl violet for visualization of the optic fiber placement with light microscopy. The adjacent unstained sections were used to assess GFP expression with fluorescent microscopy.

\section{Results}

\section{Histology}

Sixteen rats were injected with AAV9/CAG-ArchT-GFP bilaterally in the $\mathrm{VH}$ and implanted with optic fibers targeting GFPexpressing VH terminals in the PL PFC (Figs. 1A, 2A). Eight rats were injected with inactive control virus (AAV9/CAG-GFP) bilaterally in $\mathrm{VH}$ and implanted with optic fibers in PL. Four additional rats were injected with ArchT in the $\mathrm{VH}$ and a recording optrode in ipsilateral PL (Fig. 1B). Virus expression was restricted to the ventral and intermediate hippocampal formation, extending from the injection site in rostral and caudal directions by $\sim 500 \mu \mathrm{m}$. Terminal expression of GFP in the mPFC was evident throughout the rostrocaudal extent of the PL and infralimbic (IL) cortices. PL expression was strongest in the deep layers, whereas IL expression was evident in both shallow and deep layers, consistent with previous reports (Spellman et al., 2015; Marek et al., 2018). One rat in the Trial-silenced group and 2 rats in the UCS-silenced group were excluded from all analyses due to insufficient virus expression. These rats showed only artifactual GFP signal around the immediate injection site in the $\mathrm{VH}$ and no expression in the terminal field in the PFC. All rats had successful fiber placements in the PL (Fig. 2A).

\section{Electrophysiological verification}

The effect of silencing VH terminals on spontaneous PL activity was assessed in a naive rat during exploration of a habituated context. Neuronal activity was recorded during 12 trials of $70 \mathrm{~s}$ laser illumination $(15 \mathrm{~mW})$. Fifteen units were isolated from this rat. Firing during laser stimulation on each trial was converted to $Z$ scores in $1 \mathrm{~s}$ bins based on the average firing rate (Hertz) during the preceding baseline period of each trial (30 s). Figure $1 C$ shows the normalized response of each unit to photoillumination. The baseline firing rate of most (14 of 15) neurons was between 1 and $8 \mathrm{~Hz}$ and one fast-spiking neuron averaged $18 \mathrm{~Hz}$ at baseline (increasing to $22 \mathrm{~Hz}$ during photoinhibition). The majority of units (10 of 15$)$ showed a sustained ( $>50 \%$ of bins) increase in firing rate $>95 \%$ CI during photoinhibition: 2 of 15 units showed a sustained reduction in firing rate during photoinhibition, and the remaining units (3 of 15) showed no change from baseline firing. No rebound response in either direction was observed at light offset. Figure $1 D$ shows the perievent histograms and activity raster plots for example laser-responsive and laser-nonresponsive units. Thus, the predominant response of putative PL principal neurons to loss of $\mathrm{VH}$ input was an increase in firing rate that lasted throughout the laser illumination period. This is consistent with other reports of $\mathrm{VH}$ inactivation on prefrontal spontaneous activity in rats (Thierry et al., 2000; Tierney et al., 2004; Sotres-Bayon et al., 2012; Marek et al., 2018). The effect of silencing VH terminals on CS-evoked PL activity was assessed in 3 rats. These rats had $2 \mathrm{~d}$ of training, consisting of 4 CS-alone trials followed by 6 CS-trace-UCS paired trials. Laser light was delivered during the CS and trace interval of all paired trials, starting $1 \mathrm{~s}$ before CS onset and ending at shock delivery. Unit activity was analyzed on day 2 to confirm that VH-PL silencing increased spontaneous activity during baseline as it did in the naive rat and to determine whether silencing interfered with CS-evoked responses during training. Figure $1 E$ shows heat maps of average normalized firing of all units during the baseline periods of CS-alone trials (no laser delivered) and CS-paired trials (laser delivered in final second of baseline). The units are ranked based on their average activity during the last second of the baseline across trials (highest activity at the top) to compare the distribution of laser-evoked activity (Fig. $1 E$, right) with the comparable time point in laser-free sessions (Fig. 1E, left). Unit activity observed in Bin 11 of laser free CS-Alone trials (Fig. 1E, left) represents spontaneous activity normalized to baseline and did not differ from any other baseline bin (see average $Z$ score \pm SEM below heatmaps). This bin was then used to analyze the proportion of PL units that changed spike rates by $> \pm 0.5 z$ score in response to laser during the same bin of CS-paired trials in which the laser was turned on (Fig. $1 E$, right). $\chi^{2}$ test revealed that the laser significantly altered PL activity $\left(\chi_{(2,53)}^{2}=11.99, p=0.0025\right)$. Specifically, the laser significantly increased the proportion of units exhibiting increased firing ( $>0.5 z$ in magnitude) relative to baseline spontaneous firing rate ( 40 of $53>23$ of $\left.53 ; \chi_{(1,53)}^{2}=11.31, p=0.0008\right)$ and reduced the proportion of units showing reduced firing $(<-0.5$ $z$ in magnitude; 16 of $53>4$ of $\left.53 ; \chi_{(1,53)}^{2}=7.19, p=0.0073\right)$, which led to a significant immediate increase in the firing average compared with any other baseline bin (Bin $\times$ Trial interaction: $F_{(10,1040)}=6.18, p=0.000001$, all post hoc $p$ values = $0.000001)$. Thus, silencing VH input alters the excitatory-inhibitory balance of activity in PL. Terminal silencing during the CS and trace interval did not prevent CS-evoked firing on paired trials (Fig. $1 F$ ) but may have transiently altered trace interval activity compared with laser-free CS-alone trials. Figure 1 ' $G$ shows an example neuron in which trace interval activity was reduced during the first three paired trials (blue raster and histogram) compared with the preceding CS-alone trials (gray raster and histogram). We next assessed whether disruption of VH-PL communication impairs the formation of trace-cued or contextual fear memories.

\section{Cued fear learning}

The VH and PL are each necessary for the formation of cued trace fear conditioning (Runyan et al. 2004; Yoon and Otto, 2007; Czerniawski et al., 2009; Gilmartin and Helmstetter, 2010; 
A Acquisition

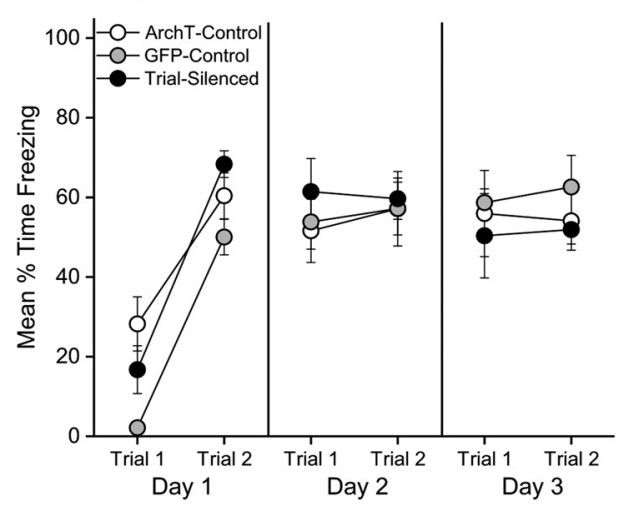

B CS Test 3

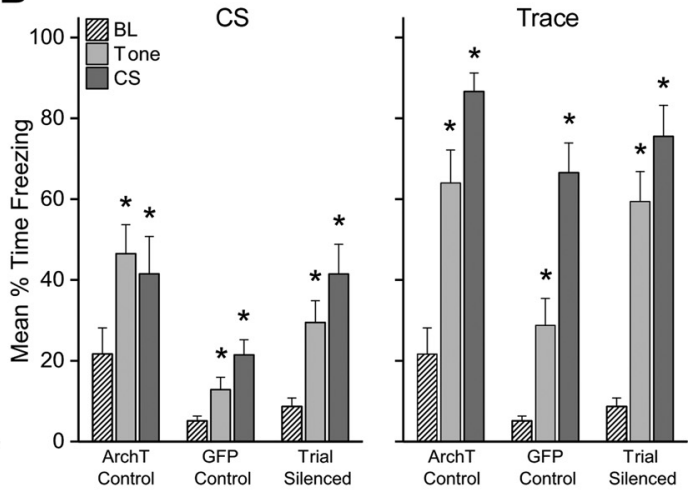

C CS and Trace Retention by Day

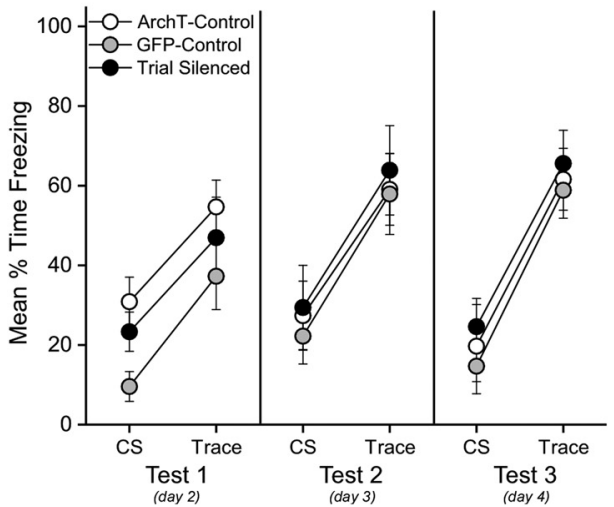

D Cue Discrimination
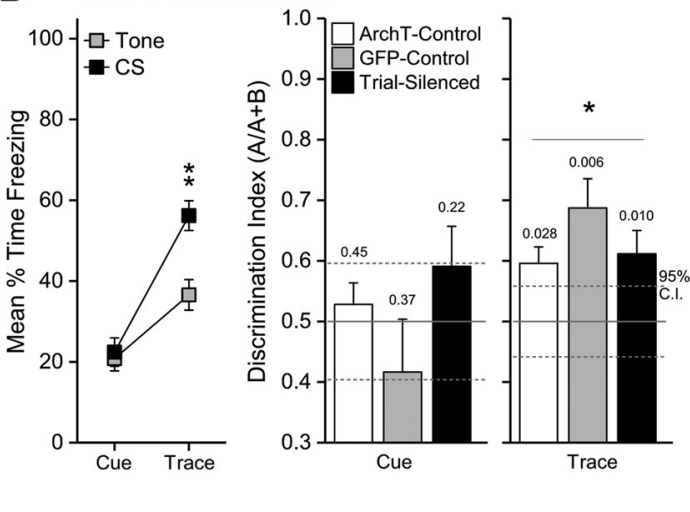

Figure 3. Silencing VH input to PL during training did not affect the formation of trace-cued fear memory. $A$, Each point represents the average ( \pm SEM) freezing during the 10 s CS and 20 s trace interval on each trial (2 trials/day) for each group: ArchT-controls $(n=8)$, GFP-controls $(n=8)$, and Trial-silenced $(n=7)$. All subjects exhibited similar levels of freezing across the 6 training trials. $\boldsymbol{B}$, Error bars indicate the average ( \pm SEM) freezing during the final $C S$ retention test, $1 \mathrm{~d}$ after the third, 2 trial session of conditioning. Left, All groups acquired conditional freezing to the CS, which generalized to the unpaired tone. Right, All groups acquired significantly more fear to the CS offset (Trace period) compared with tone offset. C, Each point represents average ( \pm SEM) baseline-subtracted freezing during the $30 \mathrm{~s} C S$ and 30 s. Trace period during each retention test (Tests 1-3). Across days, all groups show increased freezing during the Trace period compared with CS. D, Left, Each point represents the average ( \pm SEM) baseline-subtracted freezing to the cue (CS or Tone) and Trace period (CS-offset of Tone-offset), collapsed across Group and Day. All rats showed good discrimination of CS-Trace compared with unpaired Tone-Trace (Stimulus $\times$ Period: $\left.F_{(1,20)}=40.95, p<0.000001, \eta_{\mathrm{p}}^{2}=0.67\right)$. Right, Bars represent the average discrimination index for the Cue $\left(\frac{C S}{C S+u n p a i r e d t o n e}\right)$ or for the Trace period $\left(\frac{C S t r a c e}{\text { CStrace +tonetrace }}\right)$. CS-offset discrimination exceeded the $95 \%$ CI (hatched lines). The one-sample $t$ test $p$ values are reported above each group comparing the mean to the generalization point $0.5 .^{*} p<0.05$. BL refers to the baseline period before cue delivery.

Guimarais et al., 2011; Gilmartin et al., 2012, 2013a,b), and we predicted that direct communication between these areas would be indispensable for the cue-shock association across a 20 s trace interval. To test this, $\mathrm{VH}$ terminals in PL-expressing ArchT were inhibited during each trial of trace conditioning across 3 consecutive days of training ( 2 trials/day; Trial-silenced group, $n=7$ ). Control rats expressed either inactive (GFP-control, $n=8$ ) or active virus (ArchT-control, $n=8$ ). For this latter control group, the tip of the ferrule was blocked to prevent light entering the brain. This allowed us to use this control group in subsequent expression tests to test the state dependency of memory impairments. Fear to the CS and a familiar, but never paired, auditory tone cue was assessed the day after each acquisition session in a shifted context in the absence of laser light delivery. The timeline and experimental design are shown in Figure $2 B$.

Photoinhibition of VH terminals in PL during each trial of trace fear conditioning did not affect the expression of freezing during the acquisition sessions each day (Fig. 3A). This observation was supported by a significant main effect of Trials (1-6; $\left.F_{(5,100)}=21.37, p<0.0001, \eta_{\mathrm{p}}^{2}=0.52\right)$ with no effect of Group or a two-way interaction $\left(F<1 ; F_{(10,100)}=1.54, p=0.1373\right.$, respectively). Post hoc tests indicated rapid acquisition of freezing during training trials beginning with Trial 2 and no changes in CS fear expression thereafter (relative to Trial 1: $p$ values $<$ 0.0004 , all Cohen's $d_{\mathrm{RM}}>1.37$; Fig. $3 A$ ). Contrary to our hypothesis, silencing $\mathrm{VH}$ input to PL during acquisition did not prevent the formation of the cue-shock association. During the final CS retention test $1 \mathrm{~d}$ after the third and final, 2 trial training session, all groups showed greater freezing during the $30 \mathrm{~s}$ CS compared with baseline (BL; Fig. 3B, left) and greater freezing during the $30 \mathrm{~s}$ CS-offset Trace period compared with baseline (Fig. 3B, right). Although freezing to the CS generalized to the unpaired tone, freezing during the CS-offset Trace period was significantly greater than that of the unpaired tone-offset period, indicating conditional discrimination of CS-offset during trace conditioning. These observations were supported by two-way mixed-model ANOVAs on the $30 \mathrm{~s}$ cue periods and the $30 \mathrm{~s}$ cueoffset periods during the final retention session. The ANOVA on CS versus tone revealed significant main effects of Period $\left(F_{(2,40)}\right.$ $\left.=17.02, p<0.00001 ; \eta_{\mathrm{p}}^{2}=0.46\right)$ and Group $\left(F_{(2,20)}=9.15, p=\right.$ $\left.0.00151, \eta_{\mathrm{p}}^{2}=0.48\right)$ but no Group $\times$ Period interaction $\left(F_{(4,40)}\right.$ $\left.=1.54, p=0.20923, \eta_{\mathrm{p}}^{2}=0.13\right)$. Post hoc tests of Period indicated that freezing was significantly greater during both unpaired tone 
and CS presentations compared with baseline ( $p$ values $<0.05$ ), but not different between CS and tone. Post hoc tests of Group indicated only that GFP-control rats showed less freezing overall than the other groups across BL, tone, and CS periods ( $p$ values $<0.05$ ). The ANOVA conducted on the CS and tone offset (e.g., Trace) periods revealed a uniform pattern of freezing across groups. Post hoc tests of a large main effect of Period $\left(F_{(2,40)}=\right.$ 82.25, $\left.p<0.00001, \eta_{\mathrm{p}}^{2}=0.80\right)$ showed significantly increased freezing from BL for the Trace periods following either the CS or tone offset $(p$ values $=0.00001$; Cohen's $d=1.89$ and 3.88, respectively). However, discrimination was robust during the retention test as CS Trace freezing was significantly greater than unpaired tone Trace freezing ( $p=0.00001$; Cohen's $d=1.14)$. The Group factor was again significant $\left(F_{(2,20)}=11.50, p=\right.$ 0.00047, $\left.\eta_{\mathrm{p}}^{2}=0.53\right)$ but did not interact significantly with Period (Group $\times$ Period: $\left.F_{(4,40}\right)=1.40, p=0.25236, \eta_{\mathrm{p}}^{2}=$ 0.12). As with the CS analysis, post hoc tests showed only that the GFP group had overall lower freezing levels across all periods compared with ArchT-control or Trial-silenced groups ( $p$ values $<0.012$ ). These results show that VH-PL silencing did not prevent the acquisition of the cue-shock association by the end of training. This behavioral result is consistent with the observation that VH-PL silencing did not prevent CS-evoked firing in trained rats (Fig. $1 G$ ).

There was no evidence of impaired trace-cued retention across days in the Trial-silenced group. Robust CS-offset freezing was evident across days of CS testing (Fig. 3C). Mixed-model ANOVA on baseline-subtracted freezing behavior during the CS and Trace periods varying Group $\times$ Test Day $\times$ Period revealed a large effect of Period $\left(F_{(1,20)}=201.44, p<0.00001, \eta_{\mathrm{p}}^{2}=0.91\right)$ and a Period $\times$ Test Day interaction $\left(F_{(2,40)}=7.15, p=0.00221\right.$, $\left.\eta_{\mathrm{p}}^{2}=0.26\right)$ with no Group, Group $\times$ Test Day, or Group $\times$ Period interactions (all $F$ values $<1$ ). Post hoc tests revealed freezing was higher during the Trace period compared with the CS period and that this effect was largest on day 3 (all $p$ values $<0.00001$; Test day $1-3$ Cohen's $d=1.25,1.35,2.00)$. Finally, there was no effect of laser or viral manipulation on conditional discrimination to CS-offset across days. A mixed-model ANOVA revealed no meaningful interactions between Group $\times$ Stimulus $\times$ Period $\times$ Test Day $(F<1)$. Of primary interest was the significant Stimulus $\times$ Period interaction (Fig. $3 D$, left; $F_{(1,20)}$ $\left.=40.95, p<0.000001, \eta_{\mathrm{p}}^{2}=0.67\right)$ and the absence of a Group $\times$ Stimulus $\times$ Period interaction $\left(F_{(2,20)}=1.74, p=0.20177, \eta_{\mathrm{p}}^{2}=\right.$ $0.15)$, which indicated that each group showed a similar pattern of freezing across testing. Post hoc tests of the significant twoway (Stimulus $\times$ Period) interaction collapsed across groups (reported above) and for the significant Stimulus $\times$ Period interaction for each group independently (ArchT-control: $F_{(1,7)}=$ 9.488, $p=0.01781, \eta_{\mathrm{p}}^{2}=0.58$; Trial-silenced: $F_{(1,6)}=10.28, p=$ $0.01847, \eta_{\mathrm{p}}^{2}=0.63$; GFP: $\left.F_{(1,7)}=23.42, p=0.00188, \eta_{\mathrm{p}}^{2}=0.77\right)$ verified that each group froze similarly to the CS and tone, significantly increased freezing during the Trace periods relative to the cue periods and, most importantly, froze significantly more during the CS Trace compared with the unpaired tone Trace ( $p$ values $<0.0028$; Cohen's $d$ : ArchT-control, 0.91; Trial-Silenced, 1.12; GFP, 1.27). As such, this uniform pattern of freezing across groups and days indicates equivalent trace fear learning by each group. These results are further illustrated by the similar discrimination indexes of each group (Fig. 3D). Together, the results suggest that VH input to the PL during the CS-Trace-UCS pairing is not required for the PL to link the cue and shock across time in the formation of a cued trace fear memory.

\section{Contextual fear learning}

Our previous work revealed that the PL is needed for the formation of contextual fear memories during trace fear conditioning (Gilmartin and Helmstetter, 2010). A direct connection between the hippocampus and PL may convey contextual information needed for successful learning. Fear in the training context was assessed each day before training and thus afforded a detailed analysis of the acquisition of contextual fear. In contrast to tracecued fear, silencing $\mathrm{VH}$ input to the PL during training produced a persistent and temporally dynamic deficit in the formation of a contextual fear memory (Fig. 4A). The results of a mixed factorial ANOVA varying the between factor of Group by the two within factors of Bin $(10 \times 30 \mathrm{~s})$ and CT day (Pretraining, CT1CT3) revealed a significant three-way interaction $\left(F_{(54,540)}=2.47\right.$, $\left.p<0.00001 ; \eta_{\mathrm{p}}^{2}=0.20\right)$. Planned contrasts further revealed that Trial-silenced rats froze significantly less than ArchT-controls in the training context during Bins 4-9 on the first CT, and Bins 15 on second and third CTs ( $p$ values $<0.05$; Cohen's $d$ range $=0.84-2.14)$. Similarly, Trial-silenced rats froze significantly less than GFP-controls in the training context during Bins 5 and 6 on the first context retention test, Bins 1-3 on the second context retention test, and Bins $1-5$ on the third and final CT ( $p$ values $<0.05$; Cohen's $d$ range $=0.70-1.67)$. Furthermore, the significant main effect of Group $\left(F_{(2,20)}=6.34, p<0.0074 ; \eta_{\mathrm{p}}^{2}=\right.$ $0.39)$ and Group $\times \operatorname{Bin}$ interaction $\left(F_{(18,180)}=2.14, p<0.00628\right.$; $\left.\eta_{\mathrm{p}}^{2}=0.18\right)$ indicates that silencing the VH-PL pathway during training was sufficient to reduce context freezing overall compared with either GFP or ArchT-controls, but this effect was significant across days in the first few minutes of the CT (Bin 1-5 averages collapsed across days, $p$ values $<0.05$; Bin $6-10$, not significant). In light of these effects, the significant main effect of $\operatorname{Day}\left(F_{(3,60)}=178.25, p<0.0001 ; \eta_{\mathrm{p}}^{2}=0.90\right)$ and the corresponding trend for a Group $\times$ Day interaction $\left(F_{(6,60)}=2.09, p=\right.$ $\left.0.06733 ; \eta_{\mathrm{p}}^{2}=0.17\right)$ suggests that all three groups acquired increasing levels of conditional fear to the context across days with Trial-silenced rats exhibiting consistently less freezing than controls during each test. This pattern was confirmed with Bonferroni corrected post hoc tests: Trial-silenced rats froze less than ArchT-controls during CTs 1-3 ( $p$ values $<0.0125$, Cohen's $d: 1.08,1.12,2.49)$ and less than GFP-controls on CT3 ( $p=$ 0.003; Cohen's $d ; 2.78$ ); however, all groups collapsed displayed increased context fear during each test relative to the pretraining baseline day, reaching asymptotic levels on the second test $(\mathrm{BL}<$ $\mathrm{CT} 1<\mathrm{CT} 2=\mathrm{CT} 3$; $p$ values $<0.01$; Cohen's $d_{\mathrm{RM}}$ relative to preceding test day: Control $=2.49,1.53,0.39$; Trial-silenced $=1.71$, $2.39,0.30$; GFP $=2.41,1.58,1.33$ ). Therefore, despite causing a reliable deficit in contextual fear across the retention tests, $\mathrm{VH}$ PL silencing does not block all contextual fear. The fear that is acquired during VH-PL silencing is unlikely to be nonassociative, as these rats successfully discriminated between the training and testing contexts (Fig. 4B). The discrimination index $\left(\frac{A}{A+B}\right)$ revealed that context fear is increased in Context A (shock) compared with Context B (no shock) in all three groups. Nevertheless, significant context discrimination above the generalization point (0.50) was delayed in the Trial-silenced rats until the second CT day. Therefore, context fear associations formed without VH input to PL are smaller in magnitude, slower to develop, and less accurate.

The early-session context retrieval deficit was mirrored by a significantly longer latency to initiate freezing on each test by Trial-silenced rats compared with ArchT- and GFP-controls (Fig. 4C). A two-way ANOVA conducted on the latency to freeze during CTs revealed significant main effects of Group $\left(F_{(2,21)}=\right.$ 


\section{A Context Retrieval Tests}

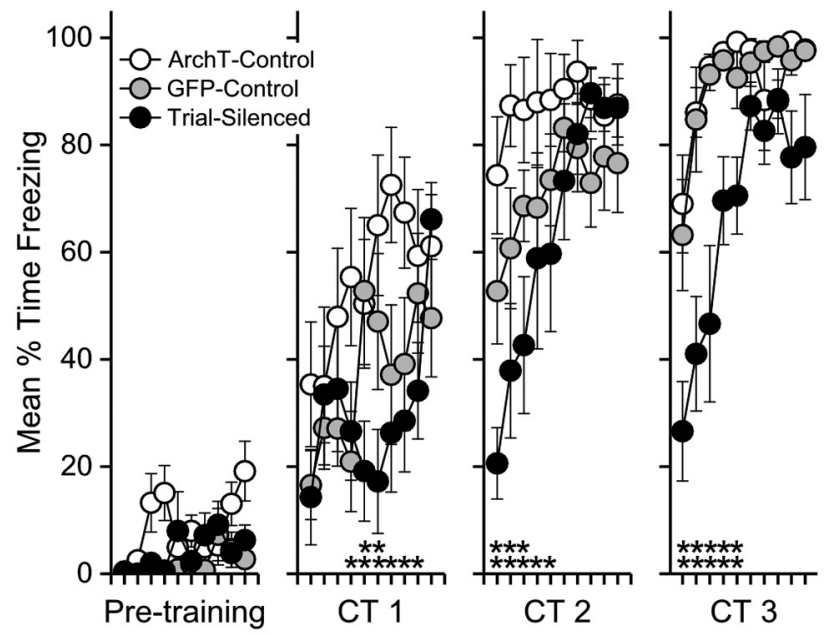

B Context Discrimination

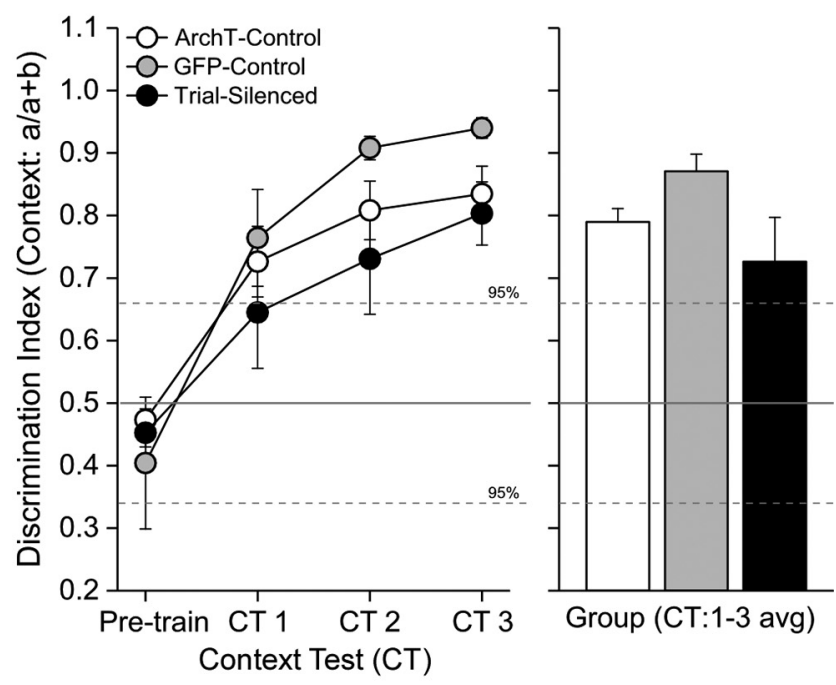

C Latency to Freeze
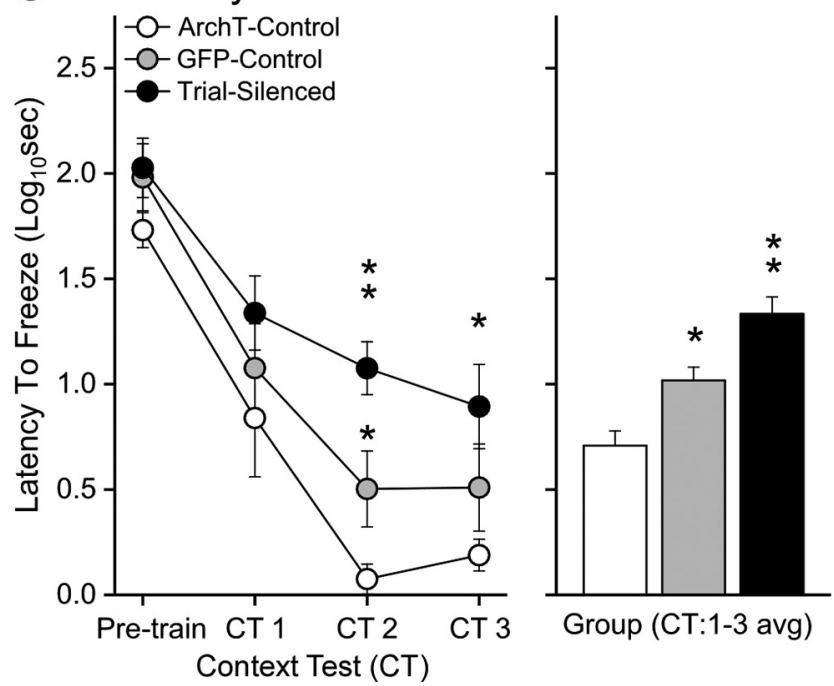

Figure 4. Silencing VH input to PL during training disrupts context fear learning. $\boldsymbol{A}$, Each point represents the average ( \pm SEM) freezing during each $30 \mathrm{~s}$ bin of the baseline period before training on day 1 (Pretraining) and during each context retention test (CT1-3, Days 2-4) before training on each subsequent day. ArchT-controls $(n=8)$, GFP-controls $(n=8)$,
21.96, $\left.p=0.00001 ; \eta_{\mathrm{p}}^{2}=0.68\right)$ and Day $\left(F_{(3,63)}=41.80, p\right.$ $\left.=0.00001 ; \eta_{\mathrm{p}}^{2}=0.67\right)$, and a nonsignificant interaction $(F<1)$. These results indicate that all three groups froze to the context more quickly across days but that the Trial-silenced rats were significantly slower to freeze overall, particularly on Tests 2 and 3 (Bonferroni-corrected contrasts: Days Pre-train to CT1: not significant, Cohen's $d=0.42,0.68$; CT2-CT3: $p$ values $<0.005$, Cohen's $d=$ vs ArchT-control $=3.65,1.75$; vs GFP-control $=$ $1.33,0.69)$. Visual inspection of each video revealed that the delay in freezing in Trial-silenced rats was not due to increased darting or escape behavior as neither was observed in these rats. Together, interruption of the VH input to the PL during each training trial disrupted the formation of contextual fear memory and impaired its subsequent expression at test.

What was striking about this finding was that contextual fear memory was significantly impaired by a relatively brief inhibition of VH input in PL. VH terminals were silenced during the 70 s encompassing each cue-shock trial, leaving communication intact during context exploration in baseline and the majority of the 4 min intertrial interval. However, VH-PL communication was disrupted both before (50 s) and after (20 s) UCS onset, raising the question of whether silencing during shock delivery would be sufficient to impair the context-shock association. Our previous work showed increased PL neuronal firing to the shock compared with baseline firing and unpaired controls (Gilmartin and McEchron, 2005), and this post-shock response may be important for learning. We thus added a group of ArchT-expressing rats (UCS-silenced group, $n=4$ ) in which laser light was delivered $1 \mathrm{~s}$ before UCS delivery and remained on for $20 \mathrm{~s}$ after the UCS. As with the Trial-silenced group, VH-PL silencing in this group had no effect on freezing during training compared with ArchT- and GFP-controls (Fig. 5A). Mixed-model ANOVA revealed only a main effect of Trial $\left(F_{(5,100)}=21.37, p<0.00001\right.$; $\left.\eta_{\mathrm{p}}^{2}=0.52\right)$ but no main effect of Group $(F<1)$, nor a Group $\times$ Trials interaction $\left(F_{(10,100)}=1.54, p=0.13731\right)$. Furthermore, a mixed-model ANOVA varying Group $\times$ Test Day $\times$ Period conducted on conditional fear during CS-Trace presentations in the test context revealed no reliable differences in learned fear between the UCS-silenced, and either ArchT- or GFP-control animals (Fig. $5 B ; F<1$ ). Indeed, the Group factor was not significant $\left(F_{(2,17)}=1.42, p=0.26981\right)$ and did not contribute to any significant interactions. The ANOVA, however, did reveal a significant main effect of Period $\left(F_{(1,17)}=146.52, p=0.00001 ; \eta_{\mathrm{p}}^{2}\right.$ $=0.90)$ and a Test Day $\times$ Period interaction $\left(F_{(2,34)}=3.41, p=\right.$

and Trial-silenced $(n=7)$. VH-PL silencing during acquisition trials impaired the subsequent expression of freezing in the absence of laser and compared with ArchT- or GFP-controls during each retention test (СT1-СТ3). ${ }^{*} p<0.05$, significantly less freezing in the Trialsilenced group relative to ArchT-controls. ${ }^{* *} p<0.05$, significance from both ArchT- and GFP-controls during each $30 \mathrm{~s}$ bin; planned comparisons of a significant three-way interaction $\left(F_{(54,540)}=2.47, p=0.0000002 ; \eta_{\mathrm{p}}^{2}=0.20\right)$. B, Context discrimination was delayed in the Trial group relative to GFP- and ArchT-controls. Each point represents the average ratio ( \pm SEM) of context elicited freezing $\left(\frac{A}{A+B}\right)$. An index $>0.5$ indicates more freezing to the training context than to the $C S$ testing context. Hatched lines indicate the $\pm 95 \%$ Cl above which indicates significant discrimination of fear. C, VH-PL silenced rats were slower to initiate freezing on each day of testing. Left, Each point represents the average latency to freeze ( \pm SEM) during each session. *Significant Bonferroni-corrected contrasts, СT2-СT3 ( $p$ values $<0.005$, Cohen's $d=3.654,1.75$ ). **Trial-silenced significantly slower than GFP-controls ( $p$ values $<0.004$, Cohen's $d$ : CT2 $=1.33$, CT3 $=0.69$, not significant). Right, Each bar represents the average latency to freeze $( \pm S E M)$ across context testing. * Significant main effect of Group $\left(F_{(2,21)}=21.96\right.$, $p=0.00001 ; \eta_{p}^{2}=0.68$, ArchT-control $<$ GFP-control $<$ Trial-silenced, all $p$ values $<0.0042$ ). 

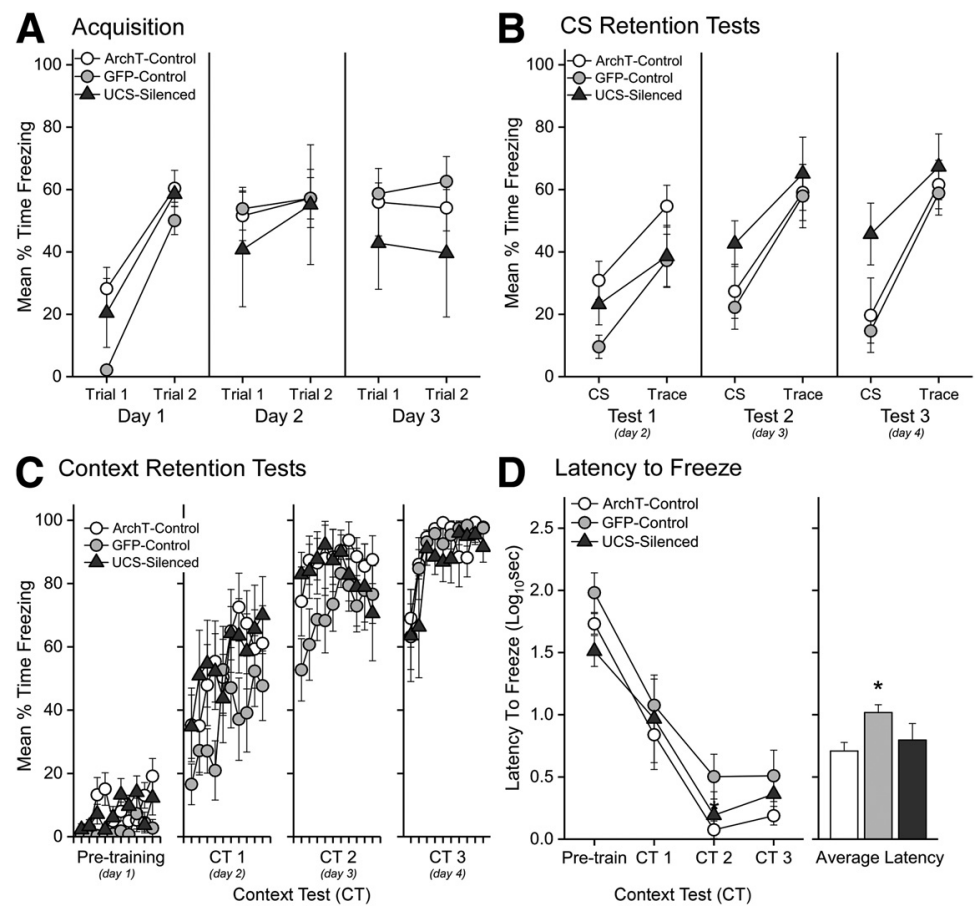

D Latency to Freeze

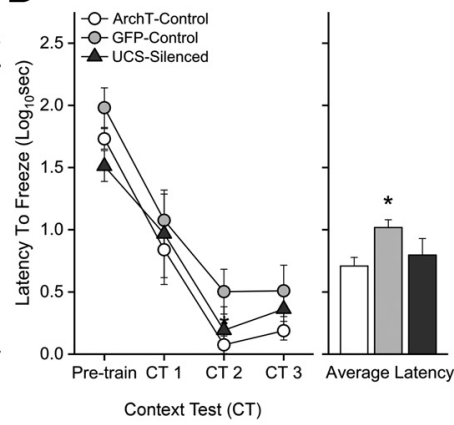

Figure 5. Silencing VH input to PL during the UCS and postshock period does not impair trace or contextual fear learning. $A-D$, ArchT- and GFP-control data are redrawn from Figures 3 and 4. A, Each point represents the average freezing ( \pm SEM) during the $10 \mathrm{~s}$ CS and $20 \mathrm{~s}$ trace interval on each trial of training (2 trials/day) for ArchT-controls $(n=8)$, GFP-controls ( $n=$ 8), and UCS-silenced ( $n=4)$. B, Each point represents the average freezing ( \pm SEM) during the $30 \mathrm{~s}$ CS and $30 \mathrm{~s}$. Trace interval of the discrete $C S$ test trials. $C$, Each point represents the average ( \pm SEM) freezing during each $30 \mathrm{~s}$ bin of the Pretraining baseline period and subsequent CTs (CT1-CT3). ArchT-Control, GFP-control, and UCS-silenced rats exhibited similar freezing across days of testing. $\boldsymbol{D}$, Graphs represent the average latency to freeze ( \pm SEM) during each session (left) and average ( \pm SEM) latency collapsed across days (right). Post hoc tests of a main effect of group $\left(\boldsymbol{F}_{(2,17)}=4.70, p=0.02369, \eta_{p}^{2}=\right.$ 0.36 ) revealed that GFP rats were slower to initiate freezing compared with the viral ArchT-controls. ${ }^{*} p<0.05$.

$\left.0.0466, \eta_{\mathrm{p}}^{2}=0.17\right)$, which indicated that rats froze significantly more during the Trace period compared with the CS period and this effect grew across days (Tests 1-3, Cohen's $d_{\mathrm{RM}}=$ $1.43,1.84,1.97)$. Finally, in contrast to the Trial-silenced group, silencing during the UCS period did not impair contextual fear (Fig. 5C,D).

A mixed-model ANOVA varying Group $\times$ Test Day $\times$ Bin confirmed that there were no differences between the groups $\left(F_{(54,459)}=1.07, p=0.34261\right)$, nor did the Group factor interact with either Test Day $\left(F_{(6,51)}=1.32, p=0.26640\right)$ or Bin $(F<1)$. Indeed, the effects of Day $\left(F_{(3,51)}=151.87, p=0.00001 ; \eta_{\mathrm{p}}^{2}=\right.$ $0.90)$ and $\operatorname{Bin}\left(F_{(9,153)}=11.99, p=0.00001 ; \eta_{\mathrm{p}}^{2}=0.41\right)$ and the Day $\times$ Bin interaction $\left(F_{(27,459)}=2.30, p=0.00028 ; \eta_{\mathrm{p}}^{2}=0.12\right)$ indicate that contextual fear is acquired and expressed at similar levels over time in the UCS-silenced, ArchT-, and GFP-control groups. Furthermore, silencing the VH-PL pathway during the UCS period did not alter the latency to initiate freezing across the CTs $(F$ values $<1$; Fig. $5 D)$. Although misplaced cannula produced a low $n$ for the UCS-silenced group, the results $(F<$ $\sim 1$ ) suggest that the variance is comparable with the other control groups and that there is no effect of reasonable size to power. These results suggest that $\mathrm{VH}$ context-related input to the PL is most crucial during the time leading up to the shock rather than during the shock and its immediate postprocessing window.

\section{Contextual state dependency for memory retrieval}

An intriguing aspect of the contextual fear memory deficit imposed by VH-PL silencing during training is that the effect, while large, is restricted to the first few minutes of each CT. This expression pattern suggests that the $\mathrm{VH}$ PL pathway normally supports the acquisition of contextual fear memories in a way that allows for the rapid retrieval and expression of the fear memory at test. One possibility is that the mnemonic deficit produced by the loss of $\mathrm{VH}$ input at encoding can be overcome through compensatory circuits that may have encoded the context shock association in parallel (e.g., hippocampal-amygdala circuits). Alternatively, because the $\mathrm{VH}$ input is not silenced at test, the delayed freezing to the context may reflect a conflict in the contextual representation of the environment at test with that previously available to the PL at encoding, when $\mathrm{VH}$ input was silenced. To test these possibilities, rats in the Trial-silenced and ArchT-control groups received two additional contextual fear tests separated by $1 \mathrm{~d}$ in which the laser light was delivered during reexposure to the training context (Fig. 6A). For CT4, light was delivered to the Trial-silenced group, which allowed both groups to be tested in the same contextual state as they had during training (Fig. 6B). For CT5, light was delivered to the ArchT-control group (which represents the first time light was allowed to reach the terminals for this group), but not to the Trialsilenced group (Fig. 6C). Importantly, this would produce a conflict in the contextual representation for both groups. If the deficit is due to a conflict in the rat's contextual state at test, then silencing this "misinformation" during the early part of the session, when the deficit is apparent, should restore adaptive fear expression. If the deficit is primarily due to an impaired memory that can be more slowly retrieved through alternate circuits, then silencing the VH-PL pathway during the early part of the session should not reverse the memory deficit.

For the Expression tests (CT4 and CT5), laser light was delivered during two 1 min periods, chosen based on the temporal pattern of freezing during the previous context retention tests (Fig. 6A): the first minute $(0-60 \mathrm{~s})$, when context fear deficits were statistically reliable during previous tests, and the fifth minute (240-300 s), when context fear was maximal for both groups during the previous tests. Figure $6 \mathrm{~B}$ shows the freezing during the first $4 \mathrm{~min}$ of CT4, in which light was delivered to the Trialsilenced group, but not ArchT-controls, during the first minute of test. Trial-silenced rats showed similar freezing as ArchT-controls while the light was on and reduced freezing compared with controls when the laser was turned off. Figure $6 \mathrm{C}$ shows the freezing during the first $4 \mathrm{~min}$ of CT5, in which light was delivered to the ArchT-controls, but not the Trial-silenced group. This was the first time the VH-PL was silenced in the ArchTcontrols. Light delivery in the first minute of test did not appear to alter the contextual freezing in ArchT-controls compared with the previous test, and once again, Trial-silenced rats (laser free) showed impaired freezing compared with controls. Figure $6 D$ shows the summary data across all CTs (Pretraining and 
A

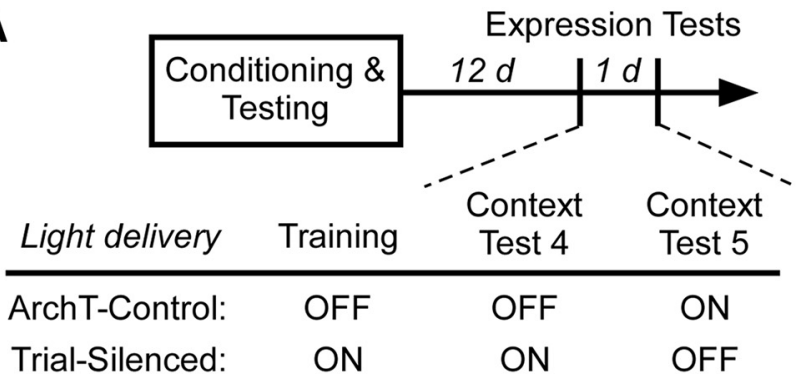

B
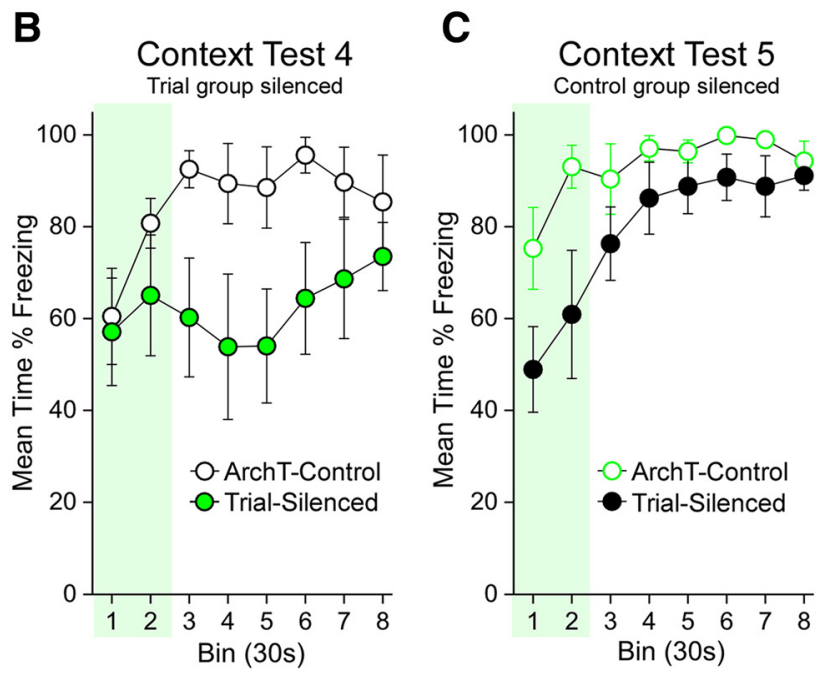

D Timing of light delivery during Expression Tests

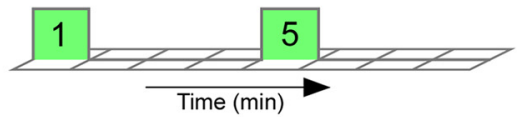

First minute of test

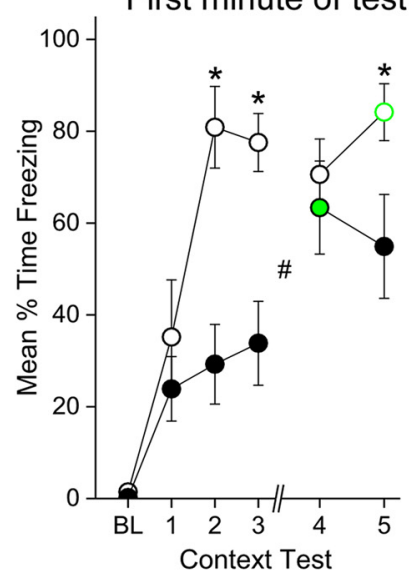

Fifth minute of test

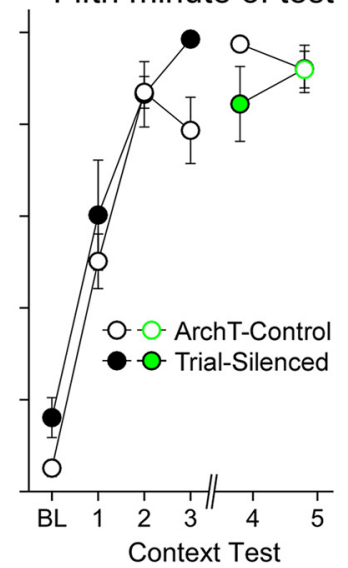

Figure 6. Silencing VH-PL during testing restores the rapid expression of contextual fear. The ArchT-controls $(n=8)$ and Trial-silenced $(n=7)$ groups received two additional CTs. $\boldsymbol{A}$, During the fourth and fifth retrieval sessions, laser light was delivered to either the Trialsilenced (Test 4) or ArchT-controls (Test 5) to test the state dependency of the contextual fear deficit. $\boldsymbol{B}, \boldsymbol{C}$, Each point represents the average freezing ( \pm SEM) in a $30 \mathrm{~s}$ bin during the first $4 \mathrm{~min}$ of retrieval testing for Test $4(\boldsymbol{B})$ and Test $5(\boldsymbol{C})$. The laser was delivered to the designated group during the first minute (green shading). $\boldsymbol{B}$, Previously impaired Trialsilenced rats exhibit control levels of fear when the VH-PL pathway is silenced again, an effect lasting only as long as the laser was on. When the laser was turned off (Bins 3-8), the retrieval deficits return and then abate, as they did during previous laser-free context testing. C, No light was administered to the Trial group, and the memory deficit is evident. Light delivered to ArchT-control rats did not affect freezing at any time point. These data are summarized in $\boldsymbol{D}$ (left). $\boldsymbol{D}$, Light was delivered during the first and fifth minute of CT4 and CT5
CT1-CT5) in this study for statistical comparison of freezing during the first minute (Fig. $6 D$, left) and during the fifth minute (Fig. $6 D$, right) of each test. Silencing VH input to PL during the first minute of the CT immediately reversed the deficit in freezing to the context in Trial-silenced rats (Test 4), but had no effect on freezing in ArchT-control rats (Test 5; Fig. 6D, left). VH-PL silencing during minute 5 had no effect on fear expression in either group (Fig. $6 D$, right). A mixed-model ANOVA varying Group (ArchT-control, Trial-silenced) $\times$ CT (BL, 1-5) $\times$ Period (Min 1, Min 5) revealed a significant three-way interaction $\left(F_{(5,65)}=3.43, p=0.0083 ; \eta_{\mathrm{p}}{ }^{2}=0.21\right)$. Holm-Sidak comparisons confirmed that silencing the VH-PL pathway in the first minute of the CT reversed the retrieval deficit compared with controls (CT4, $p=0.3807$; Cohen's $d=0.37$ ) but returned when silencing was withheld from this group the following day (CT5, $p$ $=0.0094$; Cohen's $d=1.22$ ). This effect is attributable to the significant increase in contextual freezing caused by silencing the VH-PL pathway in Trial-silenced rats during the context retrieval test compared with their low contextual freezing during the previous test (Trial group: Test 3 vs Test $4 ; p=0.0023$; Cohen's $d_{\mathrm{RM}}=1.13$ ). Importantly, VH-PL silencing had no significant effect on fear expression in the control rats during the context retrieval tests at any time, nor were there any silencing effects exhibited by either group during the second silencing period (Min 5) of context reexposure. These results suggest that contextual fear memory retrieval and expression are most efficient when the state of VH-PL communication at test matches that of acquisition. However, this is only the case when the context-shock association is acquired in the absence of $\mathrm{VH}$ input to PL. Removing VH-PL communication at test in rats in which it was intact during acquisition (i.e., ArchTcontrols) had no negative effect on memory retrieval. This suggests that the aversive memory formed in the absence of $\mathrm{VH}$ input to PL is particularly sensitive to conflicting contextual information at test.

\section{Discussion}

When the anticipation of threat demands learning about temporal or contextual cues, as in trace fear conditioning, the PFC and hippocampus are needed for memory formation. The nature of hippocampal-prefrontal cortical interaction during fear learning is unclear, however. Previous attempts to examine VH-PL communication in trace fear conditioning using pharmacological disconnection were hindered by the sensitivity of memory formation to even limited, unilateral disruption of the $\mathrm{VH}$ (Gilmartin et al., 2012). Here we used projection-targeting

$\leftarrow$

to assess state-dependent freezing before $(\min 1)$ and after $(\min 5)$ contextual fear expression was maximal in each group on previous tests. Graphs represent the summary data for all CTs in this study for the first minute (left) and the fifth minute (right). Left, Each point represents the average ( \pm SEM) freezing in the first minute of each CT when the retrieval deficit was maximal on prior tests. The data for CT4 and CT5 here are represented also in the first minute of $\boldsymbol{B}$ and $\boldsymbol{C}$. BL, Pretraining baseline freezing. BL and CT1-CT3 are presented also in Figure 4. Trial-silenced rats received VH-PL silencing again on Test 4 (green filled circle), and ArchT-control rats received silencing for the first time on Test 5 (green open circle). Right, Each point represents the average ( \pm SEM) freezing in the fifth minute of each CT when the expression of freezing was evident on prior tests. ${ }^{*} p<0.05$, between group. ${ }^{\#}<<0.05$, within group. Holm-Sidak post hoc pairwise tests of a significant three-way interaction $\left(\boldsymbol{F}_{(5,65)}=3.43, p=0.0083 ; \eta_{p}^{2}=0.21\right)$. 
optogenetics to selectively target the direct, glutamatergic projections from VH to PL to isolate the role of this connection in the formation of trace-cued and contextual fear memories. The present data show that direct communication between the $\mathrm{VH}$ and PL during trace fear conditioning is necessary for contextual fear memory, but not for trace-cued fear learning. Silencing VH input in PL produced a predominantly excitatory influence on PL spontaneous activity without preventing CS-evoked firing. The pattern of the contextual memory deficit and the disruption of local PL firing during optogenetic silencing of VH-PL suggest that the $\mathrm{VH}$ continuously updates the PL with the current contextual state of the animal, which when disrupted during memory acquisition is detrimental to the subsequent rapid retrieval of aversive contextual associations.

The hippocampus is necessary for the contextual processing of environmental stimuli and is thought to provide a contextual representation to BLA for association with the shock during fear conditioning (Maren and Fanselow, 1995; Smith and Mizumori, 2006; Fanselow, 2010). Indeed, coordinated activation of mnemonic ensembles in dorsal CA1 and BLA can produce a longlasting contextual fear memory (Ohkawa et al., 2015). However, work by us and others has demonstrated that the medial PFC normally contributes to aspects of contextual memory. Inactivation of the PL impairs background contextual fear learning, which occurs in the presence of a discrete cue predictor (Gilmartin and Helmstetter, 2010). Both the contextdriven renewal of an extinguished behavior (Sharpe and Killcross, 2015; Trask et al., 2017) and context-driven conflict resolution (Marquis et al., 2007) are impaired by PL inactivation. PL is also necessary for both latent learning about a neutral context and its subsequent association with immediate shock in the context preexposure facilitation effect design, mirroring the role of the hippocampus (Heroux et al., 2017, 2019; Robinson-Drummer et al., 2017). Related, cellular compartment analysis of temporal activity using FISH for Arc mRNA revealed that distinct PL cell ensembles encoded contextual fear memory and also contextual information independent of fear learning (Zelikowsky et al., 2014). The PFC can also compensate for hippocampal damage, supporting contextual fear learning following lesions of the dorsal hippocampus (Zelikowsky et al., 2013). These data are consistent with a coordinated hippocampal-prefrontal interaction that promotes contextual learning and context-fear associations, particularly in the face of multiple predictive cues vying for control over behavior. Our data indicate that, among the major afferents to the PFC, the VH supplies crucial contextual information needed for learning that cannot easily be provided by other circuits.

An intriguing aspect of the contextual fear deficit described in this study is that the memory impairment could be overcome with additional time in the test chamber, an effect that improved with further training. The latency to freeze decreased and contextual fear discrimination improved across days of training and testing. This suggests that the context-shock association was acquired but was not immediately accessible on reexposure to the contextual stimuli. When the laser was turned on once again during this the CT, the retrieval deficit was attenuated. This pattern of results suggests a mismatch in afferent input conveying contextual information during the test compared with training, which thus interferes with fear retrieval. This mismatch may be a result of an altered network state produced by the removal of a prominent glutamatergic input. Certainly, silencing VH terminals in PL altered the spontaneous firing rate in a subset of principal neurons, suggesting that the $\mathrm{VH}$ exerts a tonic influence on prefrontal activity. However, trace-cued fear was unaffected by this altered state, which is surprising given the importance of local firing for cued fear learning in trace conditioning (Gilmartin et al., 2013b). Thus, the selective impairment of contextual fear learning in VH-PL-silenced animals suggests that the mismatch may relate to information content differences in training versus testing. If the input from $\mathrm{VH}$ conveys the contextual state of the animal at any given time, then the absence of $\mathrm{VH}$ input at the time of training may lead to a contextual fear association based on alternative contextual input to the PL through other pathways. Recently, the nucleus reuniens of the thalamus, which mediates bidirectional hippocampal-prefrontal communication, was shown to contribute to contextual fear learning and context discrimination (Xu and Sudhof, 2013; Ramanathan et al., 2018). Interestingly, muscimol inactivation of the nucleus reuniens before fear conditioning impaired contextual fear memory in the same asymmetric state-dependent manner observed in this study. While inactivation of the nucleus reuniens before training impaired contextual retrieval at test, inactivation at both training and test prevented the impairment (Ramanathan et al., 2018). In the Ramanathan et al. (2018) study and ours, the asymmetric nature of the state dependency of the memory deficit suggests that the impairment of a node in this circuit that was intact at training is less detrimental to retrieval than permitting activity of a node that was inhibited during acquisition and now may offer conflicting information at test. One explanation for such asymmetry is that the hippocampal contextual representations conveyed via direct or thalamic input to the PL are detail-rich configural representations. Contextual memories formed in the absence of the hippocampus are elemental in nature, lacking the full configural representation encoded by the hippocampus (Maren et al., 1997; Rudy and O’Reilly, 1999). Without access to this input during training, the PL encoding of the contextual fear memory in Trial-silenced rats may have included only elemental features supplied by the amygdala or other input. In this way, retrieval in Trial-silenced rats would be impaired by the full configural representation available at test but intact if the hippocampal input were again silenced at retrieval. In comparison, control rats would be minimally affected by loss of hippocampal input at test, being able to recall the fear memory through pattern completion from elemental features (Rudy et al., 2004). It is also possible that coordinated output from $\mathrm{VH}$ to multiple targets is necessary for contextual fear memory. Recent work has implicated dual-projecting $\mathrm{VH}$ neurons to PL and BLA in context retrieval and contextual control of fear after extinction (Jin and Maren, 2015; Kim and Cho, 2017). The dual-projecting VH cells showed greater c-fos expression following contextual fear conditioning, exposure to the context without shock, or during fear renewal compared with cells projecting to only the PL or BLA (Jin and Maren, 2015; Kim and Cho, 2017). While silencing these dual-projecting cells during training did not disrupt memory formation, silencing during testing impaired retrieval (Kim and Cho, 2017). Thus, selective silencing of VH-PL input in our study leaves open the possibility that contextual encoding in the VH-BLA connection can support acquisition in the absence of direct input via VH-PL, but leads to a maladaptive fear response when VH-PL input at test interferes with memory retrieval. The state dependency of our findings suggests that the network communication at the time 
of test must match that at training for optimal retrieval of the context-shock association that was formed.

\section{Trace-cued and contextual learning are dissociated by $\mathrm{VH}$ - PL silencing}

Perhaps the most surprising finding of this study is that direct $\mathrm{VH}$ communication with the PL is not required for the cueshock association. Despite the detrimental effect on cued fear acquisition in a trace paradigm following inactivation of either the PL or the VH (Czerniawski et al., 2009; Gilmartin and Helmstetter, 2010; Guimarais et al., 2011; Gilmartin et al., 2012, 2013b), selective inhibition of the direct connection between the two areas had no effect on learning. This was somewhat surprising based on findings from trace eyeblink conditioning studies. Like trace fear conditioning, trace eyeblink conditioning in rodents and rabbits depends on the dorsal medial PFC (Weible et al., 2000), and persistent firing to trace cues is observed in deep-layer cortical cells (Siegel et al., 2012). During trace conditioning, prefrontal firing is phase-locked to hippocampal theta, and acquisition is accelerated if trials are delivered contingent on hippocampal theta (Griffin et al., 2004; Darling et al., 2011). Moreover, sustained firing to the CS in the PFC is observed during theta trials, but not non-theta trials (Darling et al., 2011), which points to coordination between the hippocampus and PFC in support of efficient cue encoding underlying associative learning. However, such coordination need not involve direct communication between the hippocampus and PFC, and our data suggest that the direct connection is preferentially involved in the encoding of contextual cues. This dissociation of cue and context encoding further indicates that the VH-PL connection in working memory may be specific to the spatial demands of the working-memory tasks commonly used in rodents rather than prospective cue encoding more broadly. Instead, nonspatial cue encoding in PL may be recruited by the amygdala and maintained via reciprocal connection with the mediodorsal (MD) thalamus. Differential recruitment of PL and IL by distinct populations of PFC-projecting BLA neurons has been described following the acquisition and extinction of cued fear (Senn et al., 2014), and CS-evoked PL firing after fear conditioning is dependent on activity in BLA (Laviolette et al., 2005; Sotres-Bayon et al., 2012). The maintenance of cueevoked PL activity may in turn be dependent on input from $\mathrm{MD}$. The MD thalamus is necessary for nonspatial associative learning during trace eyeblink conditioning (Powell and Churchwell, 2002), and the MD to PL input has recently been shown to be crucial for delay-period PL firing and spatial working-memory performance (Bolkan et al., 2017). Such PL-MD circuits may serve to integrate nonspatial and spatial inputs conveyed by distinct afferents during the formation of memory for aversive experiences.

Projection-targeting optogenetics was used in this study to overcome obstacles in previous disconnection approaches, such as unilateral inactivation effects on learning (Gilmartin et al., 2012), but terminal silencing does have its own caveats (Wiegert et al., 2017). Photostimulation of terminals expressing the enhanced ArchT construct eArchT3.0 has the capacity to increase spontaneous transmitter release at long 2-5 min stimulation periods (Mahn et al., 2016). However, it remains an effective and immediate inhibitor of terminal activity during evoked stimulation (El-Gaby et al., 2016; Mahn et al., 2016), and our use of just 2 brief 70s periods of light delivery per training session minimizes the likelihood and potential influence of spontaneous release with the related ArchT construct used here. The potential for nonspecific effects on learning due to tissue heating has been described (Owen et al., 2019), and we have previously shown that 20-33 s bouts of light alone delivered to the PL during trace fear conditioning do not impair cued or contextual fear learning (Gilmartin et al., 2013b). Likewise, $70 \mathrm{~s}$ light delivery to rats lacking the active virus in this study did not impair learning.

In conclusion, the present results suggest that direct hippocampal input to PL mediates the formation of contextual, but not trace-cued, fear memory. The contextual association laid down in VH-PL circuits may contribute to the ability of PFC to rapidly access stored contextual relationships for context-guided behavioral control, a component of flexible behavior that contributes to relapse in fear-based disorders and substance abuse (Maren et al., 2013; Goode and Maren, 2019).

\section{References}

Baeg EH, Kim YB, Jang J, Kim HT, Mook-Jung I, Jung MW (2001) Fast spiking and regular spiking neural correlates of fear conditioning in the medial prefrontal cortex of the rat. Cereb Cortex 11:441-451.

Beyeler A, Chang CJ, Silvestre M, Leveque C, Namburi P, Wildes CP, Tye KM (2018) Organization of valence-encoding and projection-defined neurons in the basolateral amygdala. Cell Rep 22:905-918.

Beyeler A, Namburi P, Glober GF, Simonnet C, Calhoon GG, Conyers GF, Luck R, Wildes CP, Tye KM (2016) Divergent routing of positive and negative information from the amygdala during memory retrieval. Neuron 90:348-361.

Bolkan SS, Stujenske JM, Parnaudeau S, Spellman TJ, Rauffenbart C, Abbas AI, Harris AZ, Gordon JA, Kellendonk C (2017) Thalamic projections sustain prefrontal activity during working memory maintenance. Nat Neurosci 20:987-996.

Cenquizca LA, Swanson LW (2007) Spatial organization of direct hippocampal field CA1 axonal projections to the rest of the cerebral cortex. Brain Res Rev 56:1-26.

Czerniawski J, Yoon T, Otto T (2009) Dissociating space and trace in dorsal and ventral hippocampus. Hippocampus 19:20-32.

Czerniawski J, Ree F, Chia C, Otto T (2011) Dorsal versus ventral hippocampal contributions to trace and contextual conditioning: differential effects of regionally selective NMDA receptor antagonism on acquisition and expression. Hippocampus 22:1528-1539.

Darling RD, Takatsuki K, Griffin AL, Berry SD (2011) Eyeblink conditioning contingent on hippocampal theta enhances hippocampal and medial prefrontal responses. J Neurophysiol 105:2213-2224.

El-Gaby M, Zhang Y, Wolf K, Schwiening CJ, Paulsen O, Shipton OA (2016) Archaerhodopsin selectively and reversibly silences synaptic transmission through altered $\mathrm{pH}$. Cell Rep 16:2259-2268.

Esclassan F, Coutureau E, Di Scala G, Marchand AR (2009) Differential contribution of dorsal and ventral hippocampus to trace and delay fear conditioning. Hippocampus 19:33-44.

Euston DR, Gruber AJ, McNaughton BL (2012) The role of medial prefrontal cortex in memory and decision making. Neuron 76:1057-1070.

Fanselow MS (2010) From contextual fear to a dynamic view of memory systems. Trends Cogn Sci 14:7-15.

Fanselow MS, Bolles RC (1979) Naloxone and shock-elicited freezing in the rat. J Comp Physiol Psychol 93:736-744.

Gilmartin MR, McEchron MD (2005) Single neurons in the medial prefrontal cortex of the rat exhibit tonic and phasic coding during trace fear conditioning. Behav Neurosci 119:1496-1510.

Gilmartin MR, Helmstetter FJ (2010) Trace and contextual fear conditioning require neural activity and NMDA receptor-dependent transmission in the medial prefrontal cortex. Learn Mem 17:289-296.

Gilmartin MR, Kwapis JL, Helmstetter FJ (2012) Trace and contextual fear conditioning are impaired following unilateral microinjection of musci$\mathrm{mol}$ in the ventral hippocampus or amygdala, but not the medial prefrontal cortex. Neurobiol Learn Mem 97:452-464.

Gilmartin MR, Kwapis JL, Helmstetter FJ (2013a) NR2A- and NR2B-containing NMDA receptors in the prelimbic medial prefrontal cortex differentially mediate trace, delay, and contextual fear conditioning. Learn Mem 20:290-294. 
Gilmartin MR, Miyawaki H, Helmstetter FJ, Diba K (2013b) Prefrontal activity links nonoverlapping events in memory. J Neurosci 33: 10910-10914.

Gilmartin MR, Balderston NL, Helmstetter FJ (2014) Prefrontal cortical regulation of fear learning. Trends Neurosci 37:455-464.

Godsil BP, Kiss JP, Spedding M, Jay TM (2013) The hippocampalprefrontal pathway: the weak link in psychiatric disorders? Eur Neuropsychopharmacol 23:1165-1181.

Goode TD, Maren S (2019) Common neurocircuitry mediating drug and fear relapse in preclinical models. Psychopharmacology (Berl) 236:415437.

Griffin AL, Asaka Y, Darling RD, Berry SD (2004) Theta-contingent trial presentation accelerates learning rate and enhances hippocampal plasticity during trace eyeblink conditioning. Behav Neurosci 118:403411.

Guimarais M, Gregorio A, Cruz A, Guyon N, Moita MA (2011) Time determines the neural circuit underlying associative fear learning. Front Behav Neurosci 5:89.

Han CJ, O'Tuathaigh CM, van Trigt L, Quinn JJ, Fanselow MS, Mongeau R, Koch C, Anderson DJ (2003) Trace but not delay fear conditioning requires attention and the anterior cingulate cortex. Proc Natl Acad Sci USA 100:13087-13092.

Heroux NA, Robinson-Drummer PA, Sanders HR, Rosen JB, Stanton ME (2017) Differential involvement of the medial prefrontal cortex across variants of contextual fear conditioning. Learn Mem 24:322-330.

Heroux NA, Horgan CJ, Pinizzotto CC, Rosen JB, Stanton ME (2019) Medial prefrontal and ventral hippocampal contributions to incidental context learning and memory in adolescent rats. Neurobiol Learn Mem 166: 107091.

Hiser J, Koenigs M (2018) The multifaceted role of the ventromedial prefrontal cortex in emotion, decision making, social cognition, and psychopathology. Biol Psychiatry 83:638-647.

Hoover WB, Vertes RP (2007) Anatomical analysis of afferent projections to the medial prefrontal cortex in the rat. Brain Struct Funct 212:149-179.

Jay TM, Witter MP (1991) Distribution of hippocampal CA1 and subicular efferents in the prefrontal cortex of the rat studied by means of anterograde transport of Phaseolus vulgaris-leucoagglutinin. J Comp Neurol 313:574-586.

Jay TM, Glowinski J, Thierry AM (1989) Selectivity of the hippocampal projection to the prelimbic area of the prefrontal cortex in the rat. Brain Res 505:337-340.

Jin J, Maren S (2015) Fear renewal preferentially activates ventral hippocampal neurons projecting to both amygdala and prefrontal cortex in rats. Sci Rep 5:8388.

Kim WB, Cho JH (2017) Synaptic targeting of double-projecting ventral CA1 hippocampal neurons to the medial prefrontal cortex and basal amygdala. J Neurosci 37:4868-4882.

Kirry AJ, Herbst MR, Poirier SE, Maskeri MM, Rothwell AC, Twining RC, Gilmartin MR (2018) Pituitary adenylate cyclase-activating polypeptide (PACAP) signaling in the prefrontal cortex modulates cued fear learning, but not spatial working memory, in female rats. Neuropharmacology 133:145-154.

Kirry AJ, Durigan DJ, Twining RC, Gilmartin MR (2019) Estrous cycle stage gates sex differences in prefrontal muscarinic control of fear memory formation. Neurobiol Learn Mem 161:26-36.

Laviolette SR, Lipski WJ, Grace AA (2005) A subpopulation of neurons in the medial prefrontal cortex encodes emotional learning with burst and frequency codes through a dopamine D4 receptor-dependent basolateral amygdala input. J Neurosci 25:6066-6075.

Mahn M, Prigge M, Ron S, Levy R, Yizhar O (2016) Biophysical constraints of optogenetic inhibition at presynaptic terminals. Nat Neurosci 19:554556.

Marek R, Jin J, Goode TD, Giustino TF, Wang Q, Acca GM, Holehonnur R, Ploski JE, Fitzgerald PJ, Lynagh T, Lynch JW, Maren S, Sah P (2018) Hippocampus-driven feed-forward inhibition of the prefrontal cortex mediates relapse of extinguished fear. Nat Neurosci 21:384-392.

Maren S, Fanselow MS (1995) Synaptic plasticity in the basolateral amygdala induced by hippocampal formation stimulation in vivo. J Neurosci 15:7548-7564.

Maren S, Aharonov G, Fanselow MS (1997) Neurotoxic lesions of the dorsal hippocampus and Pavlovian fear conditioning in rats. Behav Brain Res $88: 261-274$
Maren S, Phan KL, Liberzon I (2013) The contextual brain: implications for fear conditioning, extinction and psychopathology. Nat Rev Neurosci 14:417-428.

Marquis JP, Killcross S, Haddon JE (2007) Inactivation of the prelimbic, but not infralimbic, prefrontal cortex impairs the contextual control of response conflict in rats. Eur J Neurosci 25:559-566.

Ohkawa N, Saitoh Y, Suzuki A, Tsujimura S, Murayama E, Kosugi S, Nishizono H, Matsuo M, Takahashi Y, Nagase M, Sugimura YK, Watabe AM, Kato F, Inokuchi K (2015) Artificial association of pre-stored information to generate a qualitatively new memory. Cell Rep 11: 261-269.

Owen SF, Liu MH, Kreitzer AC (2019) Thermal constraints on in vivo optogenetic manipulations. Nat Neurosci 22:1061-1065.

Padilla-Coreano N, Bolkan SS, Pierce GM, Blackman DR, Hardin WD, Garcia-Garcia AL, Spellman TJ, Gordon JA (2016) Direct ventral hippocampal-prefrontal input is required for anxiety-related neural activity and behavior. Neuron 89:857-866.

Parent MA, Wang L, Su J, Netoff T, Yuan LL (2010) Identification of the hippocampal input to medial prefrontal cortex in vitro. Cereb Cortex 20:393-403.

Paxinos G, Watson C (2007) The rat brain in stereotaxic coordinates, Ed 6 . San Diego: Academic.

Powell DA, Churchwell J (2002) Mediodorsal thalamic lesions impair trace eyeblink conditioning in the rabbit. Learn Mem 9:10-17.

Ramanathan KR, Ressler RL, Jin J, Maren S (2018) Nucleus reuniens is required for encoding and retrieving precise, hippocampal-dependent contextual fear memories in rats. J Neurosci 38:9925-9933.

Robinson-Drummer PA, Heroux NA, Stanton ME (2017) Antagonism of muscarinic acetylcholine receptors in medial prefrontal cortex disrupts the context preexposure facilitation effect. Neurobiol Learn Mem 143:2735.

Rudy JW, O’Reilly RC (1999) Contextual fear conditioning, conjunctive representations, pattern completion, and the hippocampus. Behav Neurosci 113:867-880

Rudy JW, Huff NC, Matus-Amat P (2004) Understanding contextual fear conditioning: insights from a two-process model. Neurosci Biobehav Rev 28:675-685

Runyan JD, Moore AN, Dash PK (2004) A role for prefrontal cortex in memory storage for trace fear conditioning. J Neurosci 24:1288-1295.

Schneider M, Walter H, Moessnang C, Schafer A, Erk S, Mohnke S, Romund L, Garbusow M, Dixson L, Heinz A, Romanczuk-Seiferth N, MeyerLindenberg A, Tost H (2017) Altered DLPFC-hippocampus connectivity during working memory: independent replication and disorder specificity of a putative genetic risk phenotype for schizophrenia. Schizophr Bull 43:1114-1122.

Senn V, Wolff SB, Herry C, Grenier F, Ehrlich I, Grundemann J, Fadok JP, Muller C, Letzkus JJ, Luthi A (2014) Long-range connectivity defines behavioral specificity of amygdala neurons. Neuron 81:428-437.

Sharpe M, Killcross S (2015) The prelimbic cortex uses contextual cues to modulate responding towards predictive stimuli during fear renewal. Neurobiol Learn Mem 118:20-29.

Siegel JJ, Kalmbach B, Chitwood RA, Mauk MD (2012) Persistent activity in a cortical-to-subcortical circuit: bridging the temporal gap in trace eyelid conditioning. J Neurophysiol 107:50-64.

Sigurdsson T, Duvarci S (2015) Hippocampal-prefrontal interactions in cognition, behavior and psychiatric disease. Front Syst Neurosci 9:190.

Sigurdsson T, Stark KL, Karayiorgou M, Gogos JA, Gordon JA (2010) Impaired hippocampal-prefrontal synchrony in a genetic mouse model of schizophrenia. Nature 464:763-767.

Smith DM, Mizumori SJ (2006) Hippocampal place cells, context, and episodic memory. Hippocampus 16:716-729.

Sotres-Bayon F, Sierra-Mercado D, Pardilla-Delgado E, Quirk GJ (2012) Gating of fear in prelimbic cortex by hippocampal and amygdala inputs. Neuron 76:804-812.

Spellman T, Rigotti M, Ahmari SE, Fusi S, Gogos JA, Gordon JA (2015) Hippocampal-prefrontal input supports spatial encoding in working memory. Nature 522:309-314.

Thierry AM, Gioanni Y, Degenetais E, Glowinski J (2000) Hippocampo-prefrontal cortex pathway: anatomical and electrophysiological characteristics. Hippocampus 10:411-419. 
Tierney PL, Degenetais E, Thierry AM, Glowinski J, Gioanni Y (2004) Influence of the hippocampus on interneurons of the rat prefrontal cortex. Eur J Neurosci 20:514-524.

Trask S, Shipman ML, Green JT, Bouton ME (2017) Inactivation of the prelimbic cortex attenuates context-dependent operant responding. J Neurosci 37:2317-2324

Weible AP, McEchron MD, Disterhoft JF (2000) Cortical involvement in acquisition and extinction of trace eyeblink conditioning. Behav Neurosci 114:1058-1067.

Weible AP, O’Reilly JA, Weiss C, Disterhoft JF (2006) Comparisons of dorsal and ventral hippocampus cornu ammonis region 1 pyramidal neuron activity during trace eye-blink conditioning in the rabbit. Neuroscience 141:1123-1137.

Wiegert JS, Mahn M, Prigge M, Printz Y, Yizhar O (2017) Silencing neurons: tools, applications, and experimental constraints. Neuron 95: 504-529.
Xu W, Sudhof TC (2013) A neural circuit for memory specificity and generalization. Science 339:1290-1295.

Yoon T, Otto T (2007) Differential contributions of dorsal vs ventral hippocampus to auditory trace fear conditioning. Neurobiol Learn Mem 87: 464-475.

Zelikowsky M, Bissiere S, Hast TA, Bennett RZ, Abdipranoto A, Vissel B, Fanselow MS (2013) Prefrontal microcircuit underlies contextual learning after hippocampal loss. Proc Natl Acad Sci USA 110:99389943.

Zelikowsky M, Hersman S, Chawla MK, Barnes CA, Fanselow MS (2014) Neuronal ensembles in amygdala, hippocampus, and prefrontal cortex track differential components of contextual fear. J Neurosci 34:84628466.

Zhao MG, Toyoda H, Lee YS, Wu LJ, Ko SW, Zhang XH, Jia Y, Shum F, Xu H, Li BM, Kaang BK, Zhuo M (2005) Roles of NMDA NR2B subtype receptor in prefrontal long-term potentiation and contextual fear memory. Neuron 47:859-872. 